\title{
Structure and composition of the incisor enamel of extant and fossil mammals with tooth pigmentation
}

Structure and composition of pigmented enamel

Raquel Moya-Costa, Blanca Bauluz and Gloria Cuenca-Bescós

The inclusion of iron compounds in teeth, which impart a red to orange colour to them, is a phenomenon shown bythat several groups of vertebrates-present in different periods of their evolution. Incisors from fossil and extant shrews and from extant rodents werehave been sectioned and studied with the techniques of scanning electron microscopy (SEM), transmission electron microscopy (TEM) and scanning transmission electron microscopy (STEM) to compare their structure and the distribution of Fe. The enamel in white and red-toothed soricids has three layers; two of them are divided into two zones in the red-toothed species. However, the most external layer varies among taxa; it is well defined in Sorex but difficult to identify in the Early Pleistocene genera Beremendia or Dolinasorex. In the arvicoline rodent Terricola, only two layers can be defined,-of which the outer of whichmost is divided into two zones depending on the presence or absence of Fe. The Fe proportions in the larger soricids reach up to $45 \%$, but in rodents only up to $10 \%$ (weight \% with respect to $\mathrm{Fe}+\mathrm{Ca}+\mathrm{P}$ ). The STEM study shows that in a fossil soricid the Fe phases form clusters of nanometric particles of very poor crystalline oxides or hydroxides surrounding the apatite crystals that form the enamel.

Keywords: Soricid; Enamel; Rodent; Red teeth; EDS; TEM; Iron

Raquel Moya-Costa [raquelmc@unizar.es], Aragosaurus-IUCA, Departamento de Ciencias de la Tierra, Facultad de Ciencias, Universidad de Zaragoza, C/Pedro Cerbuna 12, 50009 Zaragoza, Spain; Blanca Bauluz [bauluz@unizar.es], IUCA, Departamento de Ciencias de la Tierra, Facultad de Ciencias, Universidad de Zaragoza, C/Pedro Cerbuna 12, 50009 Zaragoza, Spain; Gloria Cuenca-Bescós [cuencag@unizar.es], Aragosaurus-IUCA, Departamento de Ciencias de la Tierra, Facultad de Ciencias, Universidad de Zaragoza, C/Pedro Cerbuna 12, 50009 Zaragoza, Spain. 


\section{Introduction}

The skeleton is an essential solid part of the body in many groups of animals. It is formed from a mineralised tissue such as calcite or aragonite in invertebrates or apatite in vertebrates. In vertebrates the skeletal tissue is a living substance that grows with the animal, with the exception of enamel, which grows only during the formation of the teeth. The high mineral content of enamel makes this tissue the hardest in the vertebrate body. However, in some species there are other mineral phases accompanying the carbonates and phosphates. These other minerals add- new characteristics to the skeletal materials. One example is the deep-sea gastropod Chrysomallon squamiferum. This snail produces skeletal structures on its foot consisting of protection than the aragonite that forms the rest of their exoskeleton. Thist is especially useful asto be protectioned from predators (Suzuki et al. 2006; Yao et al. 2010). Another example is the presence of magnetite, goethite or ferrihydrite and lepidocrocite next to the apatite in the radula teeth of various species ofthe chitons (Polyplacophora, Mollusca)-of different species (Mizota \& Maeda 1986; Saunders et al. 2009), which that improves the self-sharpening capacity of the teeth (Wang et al. 2014). Some crabs also containhave heavy elements ( $\mathrm{Zn}, \mathrm{Mn}, \mathrm{Cu}, \mathrm{Br}$ and $\mathrm{Fe})$ in their claws, which-that provides a-higher resistance to fracture, making it easier for them to break the shell of their food (Schofield et al. 2009).The teeth of vertebrates are among the most important parts of the skeleton due to their essential uses in feeding and grooming as well as other functionsuses, including as weapons for attack or defencse (e.g. Ungar 2010). In some species, teeth have the particularity of incorporating Fe-rich phases in the enamel. The study of this kind of adaptation is interesting for an understanding of the mineralization processes in the enamel, how these change the properties of the materials, the relationship with the environment and way of life of the animal, and also in order to try to replicate these naturally occurring processes in bioengineering and medicine. 
Vertebrates with Fe-rich phases in the enamel include fishes, amphibians andor mammals, and these Fephases give them orange-red pigmentation (Suga et al. 1992; Anderson \& Miller 2011; Mao et al. 2015; Lowater \& Murray 1937; Dötsch \& Koenigswald 1978; Gomes Rodríguez 2015). Mammals with Fe-phases in their teeth are known to date back at least to thesince Cretaceous, as exemplified by fossils_such as the multituberculate Barbatodon (Smith \& Codrea 2012), but also include extant groups such as some soricids (Eulipotyphla) and rodents, which only have pigmentation in their incisors-associated with the Fe-phases in their incisors (Miles 1963; Gordon et al. 2015).

Among extant shrews only the species belonging to the subfamily Soricinae have pigmented enamel. In the fossil record there are other taxa with red teeth, such as those belonging to the subfamily Limnoecinae or to the sister family of Soricidae, Heterosoricidae (Reumer 1998). In the case of shrews the pigmented enamel varies in colour. Some species have dark red pigmentation, whereas in others the Fe-associated pigmentation is light brown or orange, more similar to rodents (Dannelid 1994). -From the moment shrews are born, they already have and use the-most of their permanent teeth (Järvinen et al. 2008), the teeth with Fe in their enamel. The adaptation constituted byrelated with the presence of Fe has been studied in several cases and hypothesized as necessary for the highrates of metabolic ratessm of those organisms that engage inassociated with continuous chewing of hard food. However, other shrews with a way of life that is scarcely different, such as crocidurines, do not have any pigmentation in their teeth. For this reason, a comparison of the two groups is needed in order to understand their differences, how exactly Fe-rich enamel affects feeding processes, and whether it is an adaptation that is more closely related with the environment or way of life or whether it depends on the phylogeny.

By contrast, rodents have pigmentation only in their incisors (Miles 1963). This is orange-brown and has the particularity of being acquired during the life of the rodent, as their incisors are ever-growing teeth 
(Wen \& Paine 2013). The structure of rodent incisors was studied for the first time by Korvenkontio (1934).

Several studies of the Fe in enamel have been carried out on soricines and rodents. One of the first studies was that by Lowater \& Murray (1937), which focused on the pigmented enamel of rats (Rodentia) and the effect of fluoride on the proportion of Fe. Recently the pigmentation in rodents has been studied in depth by Gordon et al. (2015). In soricids the pigmentation has been studied in the molars of the extant species Sorex aranaeus by Dötsch \& Koenigswald (1978); in the teeth of Sorex caecutiens and Sorex unguiculatus by Kozawa et al. (1988 a,b); and in the incisors of Blarina brevicauda by Dumont et al. (2014). Recently, and for the first time, it has been studied by Moya-Costa et al. (2018) in the incisors of two fossil shrews dating from the Quaternary, Sorex sp. and Dolinasorex glyphodon. These studies laid the foundations for the analysis of shrew enamel combining the study of structure and composition. However, all of them were performed using just one orientation of the section, so the conclusions are limited because the view is not three-dimensional. As Koenigswald (1997) stated, sections in perpendicular directions are needed in order to achievefor an accurate knowledge of the tooth to be achieved.

Furthermore, teeth are of the utmost biostratigraphical importance, being almost the only elements used in the correlation and relative dating of terrestrial basins. The reason for this is that enamel provides high resistance to decay during the fossilization processis durable, and teeth are adapted to each dietary and ecological characteristic in mammalian species. Rodents and eulipotyphlans are especially suitable for biostratigraphy and palaeoecological reconstruction during the Cenozoic, as demonstrated by variousdifferent authors seminal works such as-(e.g. Luckett \& Hartenberger (1985) andi Rzebick-Kowalska (2009).

During the final part of the Early Pleistocene (c. 1400-780 ka) ${ }_{L}$ a group of large venomous soricids with red teeth, including genera such as Beremendia, was common in faunal assemblages from Spain and 
Central Europe (Reumer 1984; Cuenca-Bescós \& Rofes 2007; Rofes \& Cuenca-Bescós 2009a; Furió et al. 2010; Botka \& Mészaros 2014; Kowalski \& Duk 2016), although they had beenwere present in Eurasia as early as the Neogene (Hoek Ostende 2005). In Spain, there weare new and even larger taxa such as Dolinasorex have been described (Rofes \& Cuenca-Bescós 2009b); although these disappeared completely towards the end of this period, during the Early-Middle Pleistocene transition. This makes them a good biostratigraphical marker.

The objective of the present study is to describe the structure of the enamel and the distribution of Fe in extant and fossil soricines using sections with different orientations, and to compare them with a soricid without pigmentation and with other, phylogenetically unrelated mammals with Fe pigmentation, such as rodents.

\section{Materials and Methods}

We selected nine incisors belonging to soricids and rodents with a view to applying different techniques to studying them. Incisors were the teeth selected because they are the biggest teeth in soricids, they are the only pigmented teeth in rodents, and they have been studied in several other works, so we can compare our results with these other studies (Dumont et al. 2014; Gordon et al. 2015; Moya-Costa et al. 2018).

Of the selected incisors, three are from recent soricids, four from fossil soricids, and two from recent rodents. The material from extant soricids and rodents comes from owl pellets from the Pyrenees (Spain) and was provided by the the Instituto Pirenaico de Ecología (IPE), which collectedrecovered them in 1967-1969. Two are lower incisors from Sorex coronatus with pigmented enamel, and one is a lower incisor from Crocidura with unpigmented enamel. The fossil teeth are lower incisors from the Early Pleistocene sites of Atapuerca (Burgos, Spain), all of them from giant shrews with pigmented enamel: three from Dolinasorex glyphodon and one from Beremendia fissidens. These fossils were obtained by the method of washing and sieving, using water to separate the clays of the sediments that fill the 


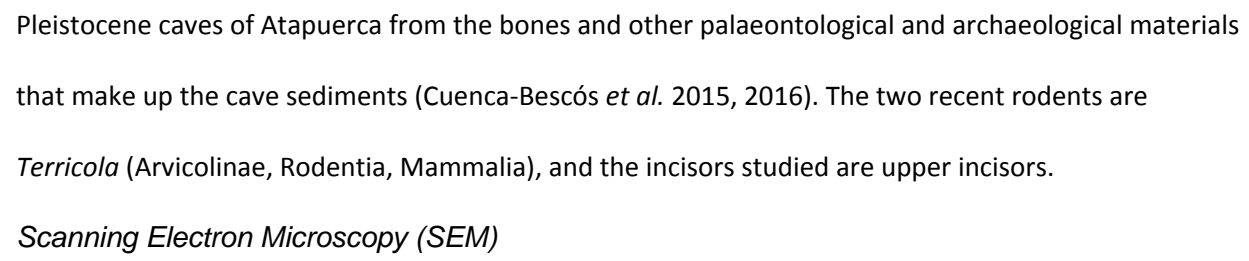


areas that, as Moya-Costa et al. (2018) describe, are not on the tooth surface. On the other hand, with this preparation the distance from the analysed points to the EDS detector is constant, and this made it possibleallowed us to semi-quantify the signals obtained and to obtain semi-quantitative results for the elements.

\section{Backscattered electron (BSE) images were taken of the sections in order to see variations in the} crystallographic and chemical compositional variations on the surface (Lloyd 1987). The detector used was mainly the angle-selective backscatter (AsB) detector, but also the energy selective backscatter (EsB) detector to see only the compositional variations. - The compositional images consist of grey colours that indicate variations in the chemical composition. The areas rich in heavy elements such as Fe show bright colours (white), whereas those areas poorer in heavy elements show darker colours. At different points of the sections semi-quantitative energy-dispersive (EDS) analyses were carried out. Most of the points are indicated in the Results section within the images taken in the Results section; and they sum a total of 108 EDS analyses were performed. The accelerating voltage was $15 \mathrm{kV}$ with a beam current of $600 \rho \mathrm{A}$ and a counting time of $50 \mathrm{~s}$ for each point. The compositional data were treated with INCA Analyser software.

With the data from the analyses and the images, a sketch of the layers and zones was drawn in each section. In soricids, the Moya-Costa et al. (2018) criterion was used; this is based on the structural characteristics (the relation between interprismatic matrix and enamel prisms) and the chemical composition. The availability of more orientations here allows a three-dimensional description of layers and zones. In rodents the same criterion-of combining structure and composition was used, with the structural differentiation here based on the previous divisions of Korvenkontio (1934) and Koenigswald (1997) and also adding the Fe distribution.

The elements detected were mainly $\mathrm{O}, \mathrm{Ca}, \mathrm{P}$ and $\mathrm{Fe}_{L}$ as well asnd very low amounts of $\mathrm{Na}, \mathrm{Mg}, \mathrm{K}, \mathrm{Al}, \mathrm{Si}, \mathrm{S}$ and $\mathrm{Ti}$ (the sum of these elements always being less than $2.5 \%$ of the total). These minor elements are 
probably in the apatite structure (Bauluz et al. 2014) but they may also come from clays and other impurities. In any case, the data were recalculated taking into account the three significant elements in this study: $\mathrm{Ca}, \mathrm{P}$ and $\mathrm{Fe}$, as explained in the Results section.

Scanning Transmission Electron Microscopy (STEM)

STEM was used to determine the structural relation between the Fe phase and the apatite in the soricid enamel, and also to infer which Fe phase is present.

This study was undertaken in the Laboratorio de Microscopías Avanzadas (LMA) of the University of Zaragoza.

To perform the TEM study, a nanometre-sized lamella was extracted from the zone with the highest Fe values in one section of a Dolinasorex incisor. Previously, the Dolinasorex incisor had been embedded in resin and cut with a diamond microtome perpendicular to the long axis of the tooth. Then, the focused ion beam (FIB) technique was used on the surface to extract a lamella of $6 \mu \mathrm{m} \times 5 \mu \mathrm{m} \times 50 \mathrm{~nm}$ using a dual-beam instrument (Helios 600).

The lamella was studiedobserved using a Tecnai F30 scanning transmission electron microscope (STEM), working atwith $300 \mathrm{kV}$ and using TEM and STEM mode. Spacings between atomic planes were determined using high-resolution TEM images with Digital Micrograph software. The d-spacing data were compared with the RRUFF Database (Lafuente et al. 2015).

A total of 17 point chemical analyses were performed using an EDS detector working ion TEM mode, and compositional images were acquired using STEM mode.

\section{Results}

Description of the sections

Here the sections inef Fig. 1 are described one by one. 


\section{S1. Transverse section of Sorex coronatus}

Fig. 2 A-K shows the compositional images of the sections of Sorex coronatus and graphs with the Fe distribution. Cracks observed in the image are probably a consequence of the process of drying and hardening-of the resin in which the teeth were embedded.

The red colour in the section coincides with the bright white of the enamel in most of the compositional image of the section. The correlation of this white with Fe is perfect, except in the area of bending (in the lower part of the tooth), which shows a red colour although the compositional image displays grey colours. This suggests that the red colour is visible in the section because the white enamel is translucent; however, but the Fe phase is not at the surface of the section, but in the enamel inside the block of resin.

Using the division of enamel reported by Moya-Costa et al. (2018), three layers with their zones in the enamel are visiblecan be observed in the BSE image.

Layer 1 (L1) is characterized by the presence of holes that correspond to sections of micron-sized tubules remaining from the adjacent dentine. The enamel is radial (Fig. 2 F). Prisms are visible; these areean be observed, being almost perpendicular to the section in the region where the enamel is thicker, in the lower part of the tooth, and almost parallel to the section in the upper part of the tooth, where only this layer is present ${ }_{L}$ with an-open prism sheaths. In the medial part, L1 gradually diminishes infeduces its thickness towards the upper part of the tooth and disappears. This layer does not contain Fe. The limit between L1 and L2 is a change in the orientation of the prisms and the loss of holes in L2. In L1 the lanceolate shapes of theprism sections run of prisms are perpendicular to the EDJ. Then they start to bend into a more parallel direction to the EDJ. Thiseir bending indicates the transition to L2. Theis change to an arrangement-shape more parallel to the EDJshape is noticeable in the upper part of the toothteeth (Fig. $2 \mathrm{E}$ ) but difficult to see in the lower part because there the change makes that the prisms-get difficult to seeobserve (Fig. 2 C). 
Layer 2 (L2) is divided into two zones. In the inner zone (Z2.1) there are some isolated tubules, although these are less abundant than in L1. At the limit between L2 and L1, prisms are not evidenteannot be distinguished in the polished section. From Z2.1 to the outer part of the enamel, Fe increases progressively. The limit between Z2.1 and Z2.2 has been markedset on the basis of the colour of the compositional image, where the image shows a brighter grey. Enamel prisms also change-a bit in orientation slightly in this band; their sections change from being elongated acicular shapes to being round in the upper part of the tooth (Fig. 2 E). The interprismatic matrix (IPM) also changes from being darker than the prisms to being whiter than they are, indicating heavier elements in the IPM than in the prisms, and possibly the presence of $\mathrm{Fe}$ in this part, although analyses do not confirm this. Fe quantities in this zone range from 0 to $20.5 \%$ at the limit with Layer 3 . L2 is visible-observed in all the section of the enamel except in the upper part of the incisor, and Z2.2 disappears where the tooth is not red, in the upper area of the medial region. Z2.2 is the zone most exposed to occlusion.

Layer 3 (L3), like L2, is divided into two zones. Zone Z3.1 is adjacent to L2. It is difficult to stabilise-fix the limit between these layers because the orientation of the prisms changes, becoming less clear, and because some entries of the darker Z3.2 are present. In Z3.1 there are high Fe concentrations (15-20\%); in contrast, Z3.2 is very dark and has low quantities of Fe (around 5\%). Z3.2 is very thin compared with Z3.1 and is even absent in part of the upper section of the tooth. Z3.2 is also very irregular, with entries into Z3.1 of $5 \mu \mathrm{m}$. The prisms are not very distinct,well distinguished but it seems that the crystals are parallel to the section, and perpendicular to the outer enamel surface (OES). In general in this section, L3 is very narrow and even absent in the upper area of the medial part.

S2. Longitudinal section of S. coronatus

Compositional images and analyses are shown in Fig. 2 L-Q. The shape of the incisor of Sorex implies that the longitudinal section is much longer in the tip-root direction than in the width, so it has to be visualized invisualization has to be done by parts. The Fe distribution determined by FESEM does not coincide exactly with the red colour in the image obtained with the binocular lens because of the shape in 3D (Fig. $2 \mathrm{~N}$ ). As the red layers cover the tooth under the section, red is seen through the transparent non-pigmented enamel in almost the whole section. 
The red region is only at the tip, where. Here at the edge the three layers with and their zones can be diistinguished.fferentiated.

The section is sufficiently far from the occlusal surface to be almost without wear, but it also has some broken areas in the enamel.

The different layers and zones are evidentcan be observed in Fig. $2 \mathrm{M}$ and Q.

L1. This is easily recognizable because of the sections of the tubules that produce holes. These tubules are perpendicular to the section close to the enamel-dentine junction (EDJ) in the tip of the tooth and become progressively more parallel to the surface, both in the direction of L2 and towards the root. The enamel prisms are not clearly distinguishableed where the tubules are perpendicular to the section, but they change in direction and in the interprismatic matrix they are more visible where the tubules are parallel to the section. Close to the root, the section of the enamel is more tangential and the prisms have an open sheath.

L2. L2 is in the whole section, from the tip to the start of the root. Tubules are scarce and small in Z2.1. The enamel prisms are lanceolate in the tip and similar to those in L3 next to the root but more elongated, changing their direction further out. In this zone Fe is absent to low (less than $5 \%$ ). Z2.2 is characterized by an increase in Fe content. Z2.2 is only in the tip and part of the lingual region, the red zones. The lances of the prisms change in direction in the tip, making an S-shape, and the IPM changes from dark grey to light grey-white. The zone is identified by a light grey colour although it is more difficult to see the prisms in the medial region. Here Fe quantities are the highest in the tip, the darkest red region, reaching up to $19.5 \%$.

L3. L3 in this section is only present in the anterior part of the section of the incisor. Here the two zones are easy toily distinguished. Z3.1, the inner one, is light grey and also contains high quantities of Fe (20\%), even higher than Z2.2. Prisms here rotate again and are not distinctguished. In Z3.2 they are wider 
OES. Fe decreases in this zone (to around $14 \%$ ).

In S._coronatus, both for S1 and S2, the results of the analyses pertainingreferred to elements other thandifferent from Fe are as follows: Ca ranges from 62.8 to $51.5 \%$, decreasing from the EDJ to the dentine, with points around the $45 \%$ in $\mathrm{Z3.1}$, where the Fe is higher. $\mathrm{P}$ also decreases from the EDJ to the OES, from 37 to $29 \%$ where Fe is higher and $34 \%$ in the OES. -As regards If consider the original values of $\mathrm{O}$, without recalculating them, these varyit varies a lot among the sections. In general they areit is lower in the dentine, and higher in Z3.2. The mean values varychanges from $40 \%$ in some sections to $30 \%$ in others. Minor elements calculated without $\mathrm{O}$ amount to lesse lower than $1.5 \%$. The most abundant of them (though still amounting to less than nut not reaching the $1 \%$ ) isare $\mathrm{Na}$, which is a bit higher in the dentine and Z3.2 than in the rest, totalling around the $1 \%$, as well as $\mathrm{Si}$ in the $\mathrm{L} 3$ and $\mathrm{S}$ in the dentine.

S3. Tangential section of the tip of the Crocidura incisor Compositional images and a sketch of the section are shown in Fig. 3. A section at the tip of the incisor of Crocidura is studied. The equivalent part in soricines is pigmented. However ${ }_{L}$ in all crocidurines this part is unpigmented.

In this section a bubble in the resin affected the bend of the lower part of the tooth. As in other soricids, three layers can be differentiated by the orientation of the prisms. Zones are not distinguishable, due toed because of the absence of Fe and consequently the lack of pigmentation. The enamel structure is radial.

L1. This is characterized by the holes resulting from the section of tubules from the dentine. Enamel prisms with lanceolate shapes are clearly distinctwell distinguished.

L2. This is a transitional layer from L1 to L3. L2 does not have pores, but it presents the same structure as $\mathrm{L} 1$ at the limit with L1, with a similar orientation and relation of the enamel prisms. $\mathrm{L} 2$ changes from a 
lanceolate-aciculate shape of prisms to open sheaths with irregular borders. At the borders of the enamel, the lanceolate shape is curved.

L3. In this layer, the structure has changed, with a different orientation of the prisms. The orientation also changes laterally from the borders of the enamel to the zone of the bend. In the part of the bend, in the lower part of the incisor, the IPM and prisms are not distinguishable, but at the borders of the enamel the prisms remain lanceolate and the orientation of the section is perpendicular to the OES. The three layers are present in all the enamel of the section, except in the uppermost region. Several EDS analyses were performed on the different layers, but they show non-significant Fe contents since the levels are below the detection threshold of the technique. $\mathrm{Ca}$ (with respect to $\mathrm{Ca}+\mathrm{P}+\mathrm{Fe}$ ) ranges from 63 to $65 \%$. $P$ has values of $23-24 \%$. As regardstfwe consider $O$, its values range from 31 to $34 \%$ in the enamel and $22-28 \%$ in the dentine. The minor elements in the onamelamount toare $1 \%$ in the enamel andwhile $2 \%$ in the dentinee $2 \%$. The highest minor elements with the highest presence are $\mathrm{Mg}$ and $\mathrm{Na}$ in the enamel and $\mathrm{S}$ in the dentine.

\section{S4. Transverse section of Beremendia}

Compositional images, analyses and the optical image are shown in Fig. 4 A-F. This incisor was broken at the tip, and its corresponding section is closer to the root than S1, S3 or S6. As in the previous cases, it has some cracks and part of the dentine is split. Several detailed BSE images were taken, but the prisms are not clearly distinctwell distinguished in the polished section.

It is remarkable that tubules are not present near the EDJ in the dentine, only in the centre of the section.

L1. Tubule holes are very scarce. In some areas, where the limits of prisms are indicated by cracks in their contacts, it can be seen that the prisms are lanceolate.

L2.The L1-L2 limit is not clear in the section, but it has been markedset where the prisms change in direction, the IPM becomes dark, and cracks perpendicular to the EDJ disappear. Poorly defined prisms change in direction across the layer. The limit between Z2.1 and Z2.2 is markedset where the image is 


\begin{abstract}
whiter and EDS analyses give high Fe contents. In the medial region Z2.2 is absent, coinciding with the absence of red pigmentation. The highest concentrations of Fe are $25 \%$.

L3. This layer is problematic in this section because the direction of the prisms is not clearly

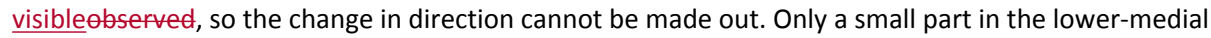
area ishas been identified as L3 because of itsthe dark grey colour (in contrast to L2), which is a consequence of the decrease in Fe, and because of the straight shape of the prisms, perpendicular to the OES. No divisions are in evidenceseen here.

In Beremendia the composition of the otherrest of elements consists of the following: Ca, which that ranges from 64.8 to $47.5 \%$ from the EDJ to OES $S_{2-}^{-} P_{2}$ with values-are from 36.4 to $28 \%$ decreasing towards the OES too; $-\mathrm{O}_{1}$ with values here are from 29 to $43 \%$, these-with aleatory values being random and that de not following a trend. The mAinor elements amount tosum $0.4-1 \%$, the most important of them being Si and $\mathrm{Na}$.

\section{S5. Longitudinal sections of Dolinasorex}

Two sections were made of this incisor at different heights. Compositional images, microphotographs andmicrophotographs and analyses are shown in Fig. 4 G-M and Fig.; 5 A-H. Here, observations onf both sections are combined. S5a is the section located higher in the tooth, closer to the occlusal plane than S5b.

The distribution of Fe does not coincide exactly with the pigmented part in the optical image because of the shape of the layer in depth (Fig. 4. H and Fig. 5 B)-.

L1. This layer is difficult to follow in the-entire tooth in its entirety because the section was too large to make detailed BSE images of the surface as a whole, so the sketch is only of the anterior part of the tooth. L1 is characterized by the presence of tubules, which in the anterior part of the tooth look like cracks because the section is parallel to them, and in the rest of the surface appearthey are seen as 
"holes". The enamel prisms are not clearly distinguishableed. Some dark edges between the sections of prisms are visibleseen, but not clearly.

L2. This layer represents most of the enamel. The L1-L2 limit is markedset where the tubules disappear. Enamel prisms are slightly more visible, but even here their shapes are not clear. Sections of the prisms look lanceolate and very elongated and are mainly perpendicular to the EDJ and OES in Z2.1, with dark limits. Zone 2.2 is defined by the appearance of Fe, which reaches values of $20 \%$. In some parts, such as-in the anterior part of $\mathrm{S} 5 \mathrm{a}, \mathrm{Z2.2}$ is not present and the OES is broken within the prisms. This seems to be due to mechanical wear.

L3. This layer is identifiableed by a change in the orientation of the prisms, which change from being perpendicular to the OES to oblique. The limit was established by the change in of orientation, but the exact position is difficult to ascertaindetermine. There is no layer with darker grey colours indicating a decrease in Fe; in fact, Fe here reaches up to $45 \%$. However, these values vary a lot within the same regions of the zone. Tłt seems that the size of the prisms and the irregular distribution of Fe seem to results in the concentration changing a lot depending on the exact point analysed. This layer is also worn in the anterior part of the tooth and is not visibleidentified in the labial part of the tooth.

\section{S6. Transverse section of Dolinasorex}

This section is made at the very tip of the cusp of the incisor of Dolinasorex. Compositional images, athe microphotopraph-microphotograph and analyses are shown in Fig. 5 I-O. Here the three layers are differentiated.

L1. As in most cases, L1 is characterized by the presence of tubule holes. THere the prism sections are clearly manifestseen, and their structure is as Koenigswald (1997) described for other mammals: "prisms squeezed between interrow sheets". The direction of the prisms and IPM (the sheet) is perpendicular to the EDJ in the inner part; they change direction in the middle and then turn perpendicular again. They form an "S" along the layer. 
Commented [RMC1]: BB1: Finish this statement. We have completed it. Maybe it was not clear before.

L1. The change to white due to the composition of Z2.2 means that the prisms become-are very clearly visible. THere the Fe contents reach up to $17 \%$.

L3. The limit is not clear; it is set-marked where the prisms change from an oblique orientation of the section to one that is to onea perpendicular to the OES- (Fig. 5 L). The Fe concentration is_here-higher than in Z2.2, as in S5. ZThe zones have not been differentiated because there are no changes in contrast in the compositional images and there is no decrease in Fe through the OES. Fe contents of $34 \%$ are found-here.

The medial region seems to be richer in Fe than the lingual region in this section.

The results of the asummarising the analyses of the elements different other thandiffering from $\mathrm{Fe}$ in S5 and $\mathrm{S} 6$ are as follows: Ca amounts to $64-33 \%$, decreasing towards the $\mathrm{OES}_{\bar{i}_{\bar{\gamma}}} \mathrm{P}$ totalsis $36.2-22.5 \%$, also decreasing towards the OES, or more exactly towards where the $\mathrm{Fe}$ is higher $\mathrm{L}_{\mathrm{L}^{-}} \mathrm{O}$ varies from 21 to $43 \%_{L}$ in general increasing towards the OES, but with values varying greatlyvery different from one section to another. The-sum of minor elements reach a total of $1.3 \%$ irrespective together independently of the point analysed. Of the minor elements, point and the $\mathrm{Si}, \mathrm{Al}, \mathrm{Mg}$ and $\mathrm{Na}$ show the highest values-of them.

$$
\text { We }
$$
are of $\mathrm{Si}, \mathrm{Al}, \mathrm{Mg}$ and $\mathrm{Na}$.

\section{S7. Tangential section of the Terricola incisor}

The compositional images and analyses are shown in Fig. 6 . This section includes the section of the pigmented and non-pigmented enamel of the incisor. Enamel is lacking in the medial part of the incisor. As it is from a rodent, the structure of the enamel is very different from that of shrews $s^{* * *}$. The terms 
referring to the parts are rather confusing due to the orientation of the cut and the curved shape of the tooth.

Two layers can be differentiated by their structure. Layer 1, the inner one with Hunter-Schreger bands (HSB), is the portio interna of Korvenkontio (1934) (Koenigswald \& Sander 1997), and Layer 2, composed of radial enamel, is the portio externa. Fe is present in the outermost zone (zone 2.2), which is very straight in comparison with shrews. This zone is maintained in all the teeth, becoming darker in the part where Fe is absent.

L1 is characterized by the rhomboid-subrounded section of the prisms in the anterior part of the enamel, with different orientations; they are elongated and trapezoidal-subrounded in the labial part. This structure is characteristic of Hunter-Schreger bands. The enamel is uniserial.

L2 starts with a sharp change in structure, which becomes more similar to shrew enamel. The prism sections are lanceolate and very elongated, or aciculate, and they are almost parallel to one another. The prism sections are much thinner than in L1, by in half or a third. The IPM between the prisms is wide on the labial side of the tooth. It is divided into two zones due to the contrast, which is related to itsthe composition. Analyses reveal that Z2.2 is pigmented enamel because it is athe zone with high quantities of Fe (up to 11\%), and it coincides with a slightly whiter zone, but Z2.2 is also present in the unpigmented enamel with a darker grey than in Z2.1, maybe as a result of its porosity. There is no change in structure linked to the presence of Fe. Nonetheless, within the part withef white enamel, a darker zone in the outermost part of the enamel is visiblecan be seen. This is the part that would correspond with the Ferich zone in the exposed tooth. For this reason, we suggest that the Fe phase would be included in this zone.

\section{S8. Transverse section of the Terricola incisor}

The compositional images, microphotograph and analyses are shown in Fig. 7. This section shows some wear mainly in the dentine of the pigmented area. Enamel covers only the anterior part of the incisor. In 
the optical image, the pigmented layer is so thin that a real layer is not visibleseen in the images; it looks like a cover for

L1 is similar to that in S7. It has Hunter-Schreger bands, with prisms in different orientations. The enamel is uniserial. The difference with respect to $S 7$ is that along the enamel the orientation of the prisms changes from one zone to another in the tangential section, though hardly at all in the transverse plane, only at the lateral ends of the enamel.

L2. The structure of the prisms changes radically to lanceolate. The sections of the prisms are perpendicular to the OES. In Z2.1 Fe is absent ${ }_{2}$ and the borders of the prisms are dark grey in the BSE images, but in Z2.2, Fe appears and the prisms become-are wider. Here the The Fe quantities reach only $9 \%$.

In L2, that was the layer analyzed, Ca ranges from 64 to $55 \%$, decreasing towards the OES. P ranges from 40 to $33 \%$, decreasing towards the OES. O values_ranges_are random, ranging-aleatory_from 21 to $38 \%$ of the total, although the amount increases as the concentrations of Fe increase-as thes increasebeing in general higher where Fe is higher too. Minor elements sum less than theconstitute $<1$

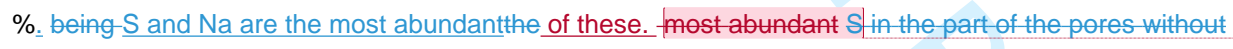
Fe and also $\mathrm{Na}$ in all the analyses.

\section{TEM in Dolinasorex: Relation between minerals}

In the TEM images two different components can be differentiated (Fig. 8): one of the components is formed by elongated prismatic and hexagonal crystals $40-50 \mathrm{~nm}$ in width. These form aggregates with parallel to subparallel crystals (Fig. 8A). According to the-EDS analyses show that; they are composed of $\mathrm{O}, \mathrm{P}$ and $\mathrm{Ca}$, indicating that, so these are the apatite crystals that form the prisms. This is confirmed by the $8 \AA$ spacing determined from the electron diffraction data and by the 4.6, 3 and $2.73 \AA$ spacings measured on the high-resolution TEM images. Their corresponding Fourier transforms (FFTs) indicate that the crystals are well-crystallized apatite (Fig. 8 B, C, F, G) As it can be observed in the STEM images show clusters of tiny, rounded particles (Fig. 9), among the aggregates of apatite crystals, the prisms, and in lower quantities between the apatite crystals, there are elusters of tiny, rounded particles (Fig. 9). These particles seem to be isometric and measure $\sim 1 \mathrm{~nm}$. Their composition They are composed consists-only of Fe and O. The high-resolution TEM images show poorly 
defined crystallographic planes and in some areas of the images the planes change in direction spatially, as though forming different domains of particles (Fig. 8 D, E). The spacing values are variable in the HRTEM images and_also in their corresponding FFTs. The most common interplanar distances measured are $d=2.15,2.15,2.65,2.95 \AA$. These variations preventdo not allow us fromto identifying clearly the type of Fe oxide (or oxyhydroxide) that forms the red zones in the tooth enamel because the spacings coincide with different minerals such as goethite, magnetite, hematite or ferrihydrite. However, theyit confirms the presence of discrete particles of Fe oxides (or oxyhydroxides).

\section{Discussion}

\section{Three-dimensional structure}

The three-dimensional structure of shrews' incisors is complex; the enamel layers are bent in different ways in the cusps, at the end and in the upper part. For this reason, any section made in the incisor would have enamel with different orientations, and it is almost impossible to obtain a section in the exact orientation that we want. In order to understand and infer the structure at least approximately, images of several incisor sections are reported in this study.

Here we have used the division of enamel established in Moya-Costa et al. (2018) on the basis of a transverse section of a fossil incisor of Sorex sp. It is important to take this into account in order to understand the differences between the zones and layers described there and in the present work. In that work $_{2}$ the conclusion-reached regarding the structure was that the incisor enamel of at least that shrew had three layers, and that the middle and outer layers were further divided into two zones.

Table 1 and Fig. 10 present a summary of the characteristics of the enamel layers of the species studied. In S. coronatus the three layers and their zones are present. Layer 3 and its zones are much thinner than in the Sorex sp. of Moya-Costa et al. (2018), probably because the section used there was closer to the tip of the incisor, where the layer is bent and the apparent thickness is greater. In Dötsch \& Koenigswald (1978) the enamel of a molar from S. aranaeus was studied, and the linear analysis also showed that Fe decreases towards the OES from an internal maximum, but the authors only mentioned the difference between the pigmented and the non-pigmented layers. In Crocidura, the zones cannot be differentiated due to the absence of Fe. However, the three layers are distinguishablecan be differentiated and seem to 
be the- same as in other shrews. The prism sections are different from in Sorex, being very irregular in L3. In the giant shrews the differentiation is more complex, as Moya-Costa et al. (2018) noted. Blarina is an extant giant shrew very similar to those studied here, and Dumont et al. (2014) describe its incisor. In their work, the prisms are clearly distinctwell distinguished except in the pigmented part, and these authorsy also differentiate three layers, althoughbut these are different from ours. In the sections of both Beremendia and Dolinasorex the three layers can be distinguished, but the divisions are difficult to discern due to the poor definition of prisms in the polished section. This could be a characteristic of these species or a consequence of possible subsequent recrystallizations of the fused apatite crystallites, as described by Koenigswald et al. (2010). However, in the pigmented zones it is easy to recognize the prisms because the brightness of $\mathrm{Fe}$ in the compositional images is clearly visible. Here the problem is that the $\mathrm{Fe}$ quantities change a lot spatially depending on the distribution of the Fe-phase clusters, as the TEM images show. In S. coronatus and Sorex sp. (Moya-Costa et al. 2018) the highest quantities of Fe are located in Z2.2-Z3.1. However, in D. glyphodon (Moya-Costa et al. 2018) the highest quantities are in Z3.1. Here in D. glyphodon we are not able to differentiate the zones in D. glyphodon, but the highest Fe quantities are also in L3. In B. fissidens we cannot make out zones, buthere the characteristics of L3 are more similar to the Z3.2 of Sorex, with a clear reductiondiminution in Fe.

In Terricola incisors two layers are visibledifferentiated. These layers correspond with the portio interna (L1) and portio externa (L2) used by previous authors (Korvenkontio 1934; Koenigswald 1980; Koenigswald \& Sander 1997; Boyde 1964). The second layer is also divided into two zones differentiated by the presence/absence of $\mathrm{Fe}$ in the pigmented part of the incisor. lHowever, in the unpigmented enamel, part Z2.2 lacks Fe but can also be differentiated by the fact thatecause it is darker than Z2.1 and forms ais the continuation of the Fe zone.

The distribution of the elements other thandifferent from Fe differsis different for $\mathrm{Ca}$ and $\mathrm{P}$ fromand the rest of the elements. $\mathrm{Ca}$ and $\mathrm{P}$ are the elements that form apatite, so their proportions are the highest and decrease where Fe increases in all the species and sections. Thislt occurs because if the proportion of $\mathrm{Fe}$ phase in the area of analysis is higher, the proportion of apatite is necessarily lower. By contrast,-On the contrary the proportion of the rest of the elements does not depend on the quantity of Fe or onf their position in the enamel. Minor elements arehave a very low in proportion, totallingin sum around $a 1 \%$ in all 
the samples. The highest minor elements with the highest presence are $\mathrm{Na}, \mathrm{S}$ and $\mathrm{Si}$. Especially $\mathrm{Na}$ is common in particular, , normal because it can replace $\mathrm{Ca}$ in apatite. $\mathrm{O}$ is also present, and its presence seems higher next to the OES. Olt is an element present in apatite but also in the Fe phase, so its variations are not very significant. All these elements appear in Blarina too (Dumont et al. 2014). The difference in this casehere is that we werehave not-been able to measure $\mathrm{C}$ as a minor element because the coating of the samples was made with this element.

\section{Composition of pigmented enamel and Fe distribution}

The Fe content with respect to $\mathrm{P}$ and $\mathrm{Ca}$ in pigmented areas is much higher in soricines (up to $45 \%$ in Dolinasorex and $25 \%$ in Sorex) than in rodents (up to $10 \%$ approximately). The distribution is also different. In some soricines, internal layers (Z2.2 in Sorex and the inner part of L3 in Dolinasorex and Beremendia) have the highest Fe quantities, whereas in rodents the most external points are the most ferruginous (Z2.2).

The highest values of $\mathrm{Fe}$ are in the longitudinal section of the Dolinasorex tooth, the darkest red enamel in this work. Therefore, the darkest red enamel coincides with the Fe-richest enamel.

An outermost layer (L3) with a lower Fe content is more clearly visiblebetter observed in the extant Sorex than in the fossil giant shrews, as in Moya-Costa et al. (2018). In this layer the difference in the definition of the enamel prisms is also noticeable; this is much clearer in the small extant shrew than in the giant fossil species.

In rodents it seems that the Fe content is higher in the external part and decreases towards the inner part. This is deduced from the chemical analyses, and it can also be inferred in other studies, such as Heap et al. (1983). In this study, which uses an acid attack on the enamel to see the prisms (etching), poor etching suggestscan be related with the highest concentrations of Fe due to its resistance to being dissolved, and this is more pronouncedworse in the outer enamel (W. v. Koenigswald, personal communication, 2017). This also coincides with Gordon et al. (2015). The advantage of using a polished section is that this makes itit is possible to seeebserve that the part with Fe also has prisms. In contrast, it is difficult to distinguish them in acid-etched samples because Fe prevents the formation of the relief topography necessary to see them. 


\begin{abstract}
In addition, the Fe distribution in each zone and layer is-differs ent among the species. In Sorex it seems
\end{abstract} that the distribution is approximately homogenous, and no significant differences are visible-detected in analyses carried out in clearer and darker parts of the compositional images similarly close to the OES. However, in Dolinasorex and Beremendia this is different. In these shrews we also performed analyses in nearby regions with different shades of grey, and the Fe quantities were found to vary a lot from one analysisfegion to another. ones.

Viewing the prisms and IPM in each layer in the compositional images of all the soricines, we note that in the enamel without Fe the IPM is usually as dark as or darker than the prisms. However, where Fe appears, the IPM isturns brighter than the prisms. This could indicate that Fe is mostly located in the IPM. In a close-up view, some small white dots or small fibres arecan also visiblebe observed inside the prisms, but these are not as abundant as in the IPM. We performed-some EDS analyses on the IPM and the prisms of the Fe-rich zones of $S$. coronatus, but we obtained similar Fe results. However, in the bigger shrews such as Beremendia or Dolinasorex, the results were different: the Fe was much higher in the brighter IPM than in the dark prisms, but $\mathrm{Ca}$ and $\mathrm{P}$ were always found in the IPM and Fe in the prisms. The reason for this might be that the prisms in Dolinasorex and Beremendia are wider than the prisms in Sorex, measuring 1-1.3 $\mu \mathrm{m}$ in Sorex and 1.5-2.5 $\mu \mathrm{m}$ in Dolinasorex and Beremendia; the width of the IPM is $0.5-1 \mu \mathrm{m}$ in Sorex and 1-4 $\mu \mathrm{m}$ in Dolinasorex and Beremendia. EDS analyses cover the approximate area of a $1 \mu \mathrm{m}$-diameter circle. Therefore, when EDS analyses are carried out on the enamel of Sorex the analyses cover an area that is more likely to contain both prisms and IPM. As a consequence, So it is not possible either to confirm or deny that they have the same composition.

In Beremendia and Dolinasorex, the analyses-would include very different proportions of prisms or IPM depending on the exact point where the analysis is made, so if the composition varies, it is easier for the results to varychange on the surface, as seen in Fig. 11. Dumont et al. (2014) point outindicate that the distribution of Fe also varieschanges a lot spatially in Blarina enamel. In the rodent incisors studied, as in the giant shrew incisors, it is more difficult to appreciate the whiter regions, but they are richer in Fe. In addition, in the section that includes pigmented and non-pigmented enamel shows, we can observe the transition in the outermost layer of the enamel. The small white spots, 
observed in compositional images, with more Fe become progressively darker as the Fe indecreases. In a wide transition area these spots are not distinguishableed from the enamel as a whole, but towards the root they are darker than the surrounding enamel, changing to dark spots. In the region of non-pigmented enamel the composition-is equal in the dark spots is equal to the rest, so the difference in tone could be due to higher porosity. It is possible that, during the development of the tooth, the Fe phase is allocated to these pores, yielding anthe orange colour when the enamel reaches the outer part of the incisor. This reasoning is also consistent with the location of $\mathrm{Fe}$ in shrews, as the brighter zones are in the IPM, which that is dark where $\mathrm{Fe}$ is not present.

Irrespective of the reasons, the fact is that in the big shrews, several point analyses and general compositional images are needed to ascertainknow in which layers the Fe quantities really are higher. It is difficult to determine exactly which layer or zone is the richest in $\mathrm{Fe}$ and to characterize the layers or zonesm when the distribution is heterogeneous. The number of EDS analyses undertakenshown in this study is significant but not necessary for characterizing the layer.

An important difference between S. coronatus and Dolinasorex+Beremendia is that the former is a fresh sample and the latter are fossils approximately 1 Ma old. However, it is noteworthycan be noted that the Fe in the studied fossils of Dolinasorex and Beremendia is not altered by diagenesis, as the fossils were buried at a depth greaterlower than $20 \mathrm{~m}$. In addition, as García-Alix et al. (2013) demonstrated, when a heavy metal surrounds a fossil, the most affected part is the dentine and cracks, but the metal does not enter the enamel, even in these small teeth. At these depths, the fFossil teeth were buried in clays containingwith carbonates from the walls of the karstic systemin these levels (Campana et al. 2017; Rofes \& Cuenca-Bescós 2009b) that could have interactedchanged with and altered their composition. Although the composition of the clays is unknown, if the teeth werehad resulted been altered the main elements that would have changed are $\mathrm{Ca}, \mathrm{P}$ and the minor elements. According to the EDS analysis, hHHowever, the composition of the fossils continues to includeremains boing $\mathrm{Ca}$ and $\mathrm{P}$ in a relation of approximately $2 / 3$, and-and the minor elements are lower than a- $2 \%$ in the results of EDS. In fact, the minor elements, especially S, are slightly higher in the extant species than in the fossil species, maybe due to remnants ofaining organic material. $\mathrm{Na}$ is around the $1 \%$, possibly replacing the Ca in apatite. In the dentine, thawhich 
that could be related with the carbonate in the water of the karstic system, but in the extant teeth the proportion is similar, suggesting thate it is normal ien teeth.

Throughout this study, we refer to Fe forming a mineral phase in the structure of enamel. In contrast, sometimes it is possible to find traces of $\mathrm{Fe}$ in the apatite of non-pigmented remains such as bones. In these cases, Fe substitutes $\mathrm{Ca}^{2+}$ ions (Okazaki 1991); the Fe quantities are much smaller, as occurs in all animals, including for example humans (e.g. Tompsett 1935; Lowater \& Murray 1937; Williams \& Siegele 2014).

\section{Wear of the teeth}

IIn the-sections of Dolinasorex sections (first longitudinal section and transverse sections S5 and S6) showitcan be observed that the wear of the teeth at the incisor tip has destroyed the external layers. The low-Fe--content layer seems to be worn away easily, but at some points the wear also completely affects the Fe-rich part. This ishas also-been observed in other sections, such as the transverse section of Beremendia (S4), probably because the Fe-rich part is so close to the tip.

This observation might be taken tocould corroborate the hypothesis that posits the function of "ferruginous enamel" as reducing tooth wear because it is quickly exposed, as proposed by Vogel (1984), Dumont et al. (2014) and Strait \& Smith (2006) and opposed by Moya-Costa et al. (2018). On the other hand, in some extreme situations, this part of the enamel can also be worn awayeut and the white enamel exposed, so the function is limited although it may apply in part of the animal's life.

It is important to remark that originally the ferruginous enamel is not at the enamel surface, at least in some species. This goes for certainsome species belonging to the genus Sorex (S. coronatus in the present work, S. aranaeus in Dötsch \& Koenigswald 1978, andor the fossil Sorex sp. of Moya-Costa et al. 2018) and Dolinasorex. Söderlund et al. (1992) and Dannelid (1994) point out that the pigmented enamel of Sorex is not, or is not always, harder than unpigmented enamel, but these authors consider the pigmented enamel to be the outermost layer. We have also observed that usually the wear is more intense in the outer part of the pigmented enamel. With the Fe distribution that we propose, these observations would not imply that the layer with iron is not the hardest. In other words, the hardness of enamel mayєan indeed be directly related with the presence of Fe.
Commented [RMC6]: BB5:If this is the normal composition there is not need for the explanation in the earlier portion of the sentence.

We had explained it as response to the comments of the reviewer that wanted an explanation about the minor elements and the possible affection of the clays to the composition of fossils. We are demonstrating that they have not been affected. 
The situation is different in rodents, as shown by the study of the tangential section, which is supposed not to be affected by wear. The Fe layer is completely external in the pigmented enamel and continues towards the white enamel with a change in greys in the compositional image.

This is not surprising. There are many differences between rodent pigmented enamel and soricine pigmented enamel: 1) the colour, i.e. yellow-orange to light brown in rodents and light-dark red in shrews; 2) the process of formation, which continues throughout rodent life but only occurs before birth in shrews; 3) possibly, though not definitely, the composition, i.e. ferrihydrite in rodents (Gordon et al. 2015) and magnetite (Dumont et al. 2014) or goethite (Akersten 2001, 2002) in shrews; and 4) the spatial distribution and percentages of Fe discussed here. The main points of coincidences_-are that the most abundant "uncommon" abundant element is Fe and that this imparts coloration to the enamel. For this reason, it is possible that the incorporation of $\mathrm{Fe}$ in enamel is not a rare process in vertebrates, that there are different ways to develop this adaptation, and these can generate different advantages. -Dannelid (1994) also pointed out that the different species of shrews have undergone parallel evolution in their pigmentation, which depends more on the environment than on their phylogenetic relations.

\section{TEM: Minerals and relations}

High-resolution TEM images have allowed the presence of two very different phases to be determined: the apatite and the Fe-rich phase. The poorly=crystallized Fe phase consists of $1 \mathrm{~nm}$ particles that form aggregates among the large, well-crystallized apatite crystals. The FESEM shows the occurrence of-Ferich zones, but only the TEM is able tocan image the Fe-rich particles and their distribution. The combination of the TEM images with chemical analyses indicates that these phases are formed by Fe and $\mathrm{O}$, although the presence of hydrogen cannot be ruled out because $\mathrm{H}$ is undetectable by this technique. On the other hand, the high-resolution images suggest that they are poorly crystalline phases that aggregate to generate rounded domains that form clusters. The different sizes of the clusters of $\mathrm{Fe}$ particles are also the reason that the results of the analyses are different in each species and at each analytical point. WhenThe larger the cluster is larger, the smaller is the influence of the surrounding apatite has less influence o-on the EDS analysis.

Dumont et al. (2014) undertook TEM studies on the pigmented enamel of a shrew, Blarina, and their they also argueconclude thatconclusion was also that with TEM analyses alone it is not possible to ascertain 
thecannot identify -the mineral containing Fe. Combining this techniqueTEM analysis-data with X-ray photoelectron spectroscopy (XPS) and X-ray diffraction analysis (XRD), they conclude that the Fe phase is magnetite in Blarina, It so it could be the same mineral in Dolinasorex, since this is, for this is one of the minerals consistent with the results. On the basis of On the basis ofBased on EDTA and X-ray diffraction, however, Akersten et al. $(2001,2002)$ argued that the Fe-rich mineral in Blarina is goethite, another mineral thatwhich also fits_the-TEM results $;$, The ferrihydrite of rodents (Gordon et al. 2015) is also consistent withfits the results. W-so we do not rule out this out eitherany of these minerals. In fact, the ferrihydrite of rodents (Gordon et al. 2015) also fits the results.

Dolinasorex could be a similar case to Blarina, given that its Fe minerals are also formed by nearly amorphous nanocrystals and the colour of the pigmentation is a similar, dark red. Even if the Fe oxides are the same in both cases, the important issue is that the fossilization process does not seem to have modifiedmodify the Fe phase.

Here it is shown that Fe nanoparticles do not form well-defined domains. This is very similar to the situation described in Banfield et al. (2000), who. Banfield et al. (2000) describe the microstructure of some biomineralizations of oxyhydroxides; they observe that Fe compounds form nanometric crystals and that the mineral changes according to the size of the aggregations. The mineral may, for example, be ferrihydrite, goethite or hematite. This could be-a case similar to the shrew enamel studied here, given the small size of the crystals, the changes in planar orientation within the aggregates, and the difficulty of knowing the mineral exactly.

Accordingly For this reason, it is also possible that the Fe-rich phase changes from one region to another within the same tooth. In shrews the pigmentation is mainly red, but with different tonalities, ranging from yellow to garnet, so this could be produced by different minerals depending on the species too. In addition to the hypothesized occurrence of different Fe phases, as we can infer from this study, the change inof colour may also be a consequence of the thickness of the pigmented layers. The red is darker in Beremendia and Dolinasorex than in Sorex. If we compare the TEM images of Blarina in Dumont et al. (2014) and the Dolinasorex of the present study, the difference is that here the apatite crystals are not always parallel to one another, whereas in the Blarina lamella they look parallel. In the Dolinasorex lamella, it can be observed that there is a relation 
between the Fe compound and the change in the orientation of the apatite, the largest clusters being in the gaps between prism aggregates.

\section{Conclusions}

$\underline{\text { We have discovered that Fe oxides or hydroxides, which causers of the pigmentation of teeth inef }}$ soricines and rodents, are located in the interprismatic matrix of the enamel in the form of aggregates of nanoparticles. Among the different species of shrews, the enamel structure is similar, consisting ofbased in three layers even in the species without pigmentation. However, the distribution of Fe variesis slightly differentamong different clades. In Sorex the enamel zones-of enamel with the highest concentrations of Fe are internal, whereas in the large-bigsized species from the Early Pleistocene the distribution of $\underline{F e}$ in the outermost layer is not so clear. In contrast, the structure in rodents is different, comprisingwith only two layers. Fe in rodents is located close to the surface and in lower proportions than in shrews. -In rodents it is notables the incisor is the part where the inctly the apatite is depositedthe apatite; -and subsequentlyafterthat, in the spaces among crystals, it is deposited the Fe compound is deposited.

$\underline{\text { In sSummaryizing, the structure of enamel is similar among species that are phylogenetically closely }}$ related. DSomedifferent orders such as Soricidae and Rodentia have in common the inclusion of Fe in their enamel, although it may take different formss performed in a different way.

The distribution of iron in the incisors of different groups of mammals with pigmented enamel, such as soricids and rodents, is variablet.

The distribution of layers of enamel is similar among the four species of soricids studied here, including the non-pigmented species, but it differs from that in rodents.

In Sorex there is a clear outermost zone with Fe quantities lower than in the inner zones, but not in Terricola. In the giant shrews Dolinaserex and Beremendia it seems that the Fe decreases towards the OES, but the spatial distribution of $\mathrm{Fe}$ is random.

The Fe-rich phase is concentrated mostly in the IPM, but we can only see this in enamel with sufficiently targe prisms such as Dolinasorex or Beremendia. In Sorex, which has small prisms, the analyses are representative of an area with both IPM and prisms, so the results in each zone are more homogoneous. 


\begin{abstract}
The TEM data show that Fe compounds are oxides or oxyhydroxides and form very small nanoparticles (1
\end{abstract} $\mathrm{Am}$ in diameter) that are grouped in clusters mainly in the sheaths of prisms, covering them and occupying cavities. The Fe-rich phase might differ among species or within the same tooth due to the different size of the aggregates of nanoparticles.

Higher Fe quantities in rodents are present in the outermost layer, unlike in shrews, and Fe is absent in the white part of the incisor, where instead of it there are-only pores.

\section{Acknowledgements}

The work was funded by the MINECO and MINECO/FEDER projects CGL2012- 38434-C03-01, CGL2015-65387-C3-2 and CGL2013-46169-C2-1-P and Grupos Consolidados del Gobierno de Aragón H54E18 17R. RMC is the beneficiary of a subsidy from the MECD (FPU14/05528).

The authors would like to-acknowledge the use of the Servicio General de Apoyo a la Investigación-SAI, Universidad de Zaragoza ${ }_{1}$ and the LMA-INA for-offering_access to their instruments and expertise.

The recent material was provided by Juan Pablo Martínez Rica of the Instituto Pirenaico de Ecologia (CSIC).

The pigmentation in vertebrate teeth was discussed with J. J. Negro.

The authors also want to-acknowledge the help, explanations and discussions on shrew enamel offered by Professor W. v. Koenigswald during a visit to his laboratory in Bonn in 2017. We have no conflict of interests to declare.

\section{References}

Akersten, W.A., Lowenstam, H.A., Walker, A. \& Biknevicious, A.R. 2001: Composition, genesis, and function of shrew tooth "pigmentation". Journal of Morphology 248, 201-201. Akersten, W.A., Lowenstam, H.A., Walker, A., Traub, W. \& Biknevicious, R. 2002: How and why do some shrews have red teeth? Journal of Vertebrate Paleontology 22, 31-31. Anderson, M.A. \& Miller, B.T. 2011: Early Iron Deposition in Teeth of the Ambystoma barbouri. Journal of Herpetology 45, 336-338.

Commented [RMC12]: BB11: Are the pores and cavities the
same thing? If so, pick one term or the other and use that term
througout the paper.
No they are not exactly the same thing. No they are not exactly the
same thing. We have changed the word and explained better
Commented [RMC13]: BB12: Do they or don't they? Can this
not be determined?
This can not be determined, this is what we suppose as we explain
in the results of TEM.


Banfield, J.F., Welch, S.A., Zhang, H., Ebert, T.T. \& Penn, R.L. 2000: Aggregation-Based Crystal Growth and Microstructure Development in Natural Oxyhydroxide Biomineralization Products. Science 289, $751-$ 754.

Bauluz, B., Gasca, J.M., Moreno-Azanza, M. \& Canudo, J.I. 2014: Unusual replacement of biogenic apatite by aluminium phosphate phases in dinosaur teeth from the Early Cretaceous of Spain. Lethaia 47. $\underline{556-566 .}$

Botka, D. \& Mészaros, L. 2014: Beremendia (Mammalia, Soricidae) remains from the late Early Pleistocene Somssich Hill 2 locality (Southern Hungary) and their taxonomic, biostratigraphical, palaeoecological and palaeobiogeographical relations. Fragmenta Palaeontologica Hungarica 31, 83-115. Boyde, A. 1964: The Structure and Development of Mammalian Enamel. Unpublished Doctoral dissertation, University of London.

Cuenca-Bescós G. \& Rofes J. 2007: First evidence of poisonous shrews with an envenomation apparatus. Naturwissenschaften 94, 113-116.

Cuenca-Bescós, G., Blain, H.A., Rofes, J., Lozano-Fernández, I., López-García, J.M., Duval, M., Galán, J. \& Núñez-Lahuerta, C. 2015: Comparing two different Early Pleistocene microfaunal sequences from the $\underline{\text { caves of Atapuerca, Sima del Elefante and Gran Dolina (Spain): Biochronological implications and }}$ significance of the Jaramillo subchron. Quaternary International 389, 148-158.

Cuenca-Bescós, G., Blain, H.-A., Rofes, J., López-García, J.M., Lozano-Fernández, I., Galán, J. \& NúñezLahuerta, C. 2016. Updated Atapuerca biostratigraphy: Small-mammal distribution and its implications for the biochronology of the Quaternary in Spain. Comptes Rendus Palevol 15, 621-634.

Dannelid, E. 1994: Comparison of pigment and other dental characters of eastern paleoartic Sorex (Mammalia: Soricidae). Advances in the Biology of Shrews. Pittsburgh, United States.

Dumont, M., Tütken, T., Kostka, A., Duarte, M.J. \& Borodin, S. 2014: Structural and functional characterization of enamel pigmentation in shrews. Journal of Structural Biology 186, 38-48. Dötsch, V.C. \& Koenigswald, W.v. 1978: Zur Rotfärbung von Soricidenzähnen. Zeitschrift für Säugetierkunde 43, 65-70.

Furió M., Agustí J., Mouskhelishvili A., Sanisidro O. \& Santos-Cubedo A. 2010: The Paleobiology of the Extinct Venomous Shrew Beremendia (Soricidae, Insectivora, Mammalia) in Relation to the Geology and 
Paleoenvironment of Dmanisi (Early Pleistocene, Georgia). Journal of Vertebrate Paleontology 30, 928 942.

García-Alix, A., Minwer-Barakat, R., Martín Suárez, E., Freudenthal, M. \& Delgado Huertas, A. 2013:

Cinnabar mineralization in fossil small mammal remains as a consequence of diagenetic processes. Lethaia 46, 1-6.

Gomes Rodrigues, H. 2015: The great variety of dental structures and dynamics in rodents: new insights into their ecological diversity. In Cox, P.G., \& Hautier, L. (eds): Evolution of the Rodents: Advances in Phylogeny, Functional Morphology and Development, 424-447. Cambridge University Press, Cambridge, CBG.

Gordon, L.M., Cohen, M.J., MacRenaris, K.W., Pasteris, J.D., Seda, T. \& Joester, D. 2015: Amorphous intergranular phases control the properties of rodent tooth enamel. Science 347, 746-750.

Heap, P.F., Berkovitz, B.K.B., Gillet, A.S. \& Thompson, D.W. 1983: An analytical Ultrastructural Study of the Iron-rich Surface Layer in Rat-incisor Enamel. Archives of Oral Biology 28, 195-200.

Hoek Ostende, L., Doukas, K., Reumer \& J.W.F. 2005: The Fossil Record of the Eurasian Neogene insectivores (Erinaceomorpha, soricomorpha, Mammalia), Part I. Scripta Geologica 5, 1-300. Koenigswald, W.V 1980: Schmelzmuster und Morphologie in den Molaren der Arvicolidae (Rodentia). Abhandlungen der Senckenbergischen natuiforschenden Gesellschaft 539, 1-129.

Koenigswald, W., 1997: Chapter 12. Evolutionary trends in the differentiation of mammalian enamel ultrastructure. In Koenigswald, W. \& Sander, P.M. (eds): Tooth enamel microstructure, 203-235. Balkema, Rotterdan, RTM. Koenigswald, W. \& Sander, P.M, 1997: Chapter 15. Glossary of terms used for enamel microstructures. In Koenigswald, W. \& Sander, P.M. (eds): Tooth enamel microstructure, 203-235. Balkema, Rotterdan, $\underline{\text { RTM. }}$

Koenigswald, W.v., Kalthoff, D. C. \& Semprebon, G.M. 2010: The microstructure of enamel, dentine and cementum in advanced Taeniodonta (Mammalia) with comments on their dietary adaptations. Journal of Vertebrate Paleontology 30, 1797-1804. 
Korvenkontio, V.A. 1934: Mikroskopische Untersuchungen an Nagerincisiven unter Hinweis auf die Schmelzstruktur der Backenzahne. Histologischphyletische Studie. Annales Zoologici Societatis Zoologicae-botanicae Fennice Vanamo 2, 1-280.

Kowalski, K. \& Duk, K. 2016: Kopalne ssaki jadowite z nadrzędu Eulipotyphla. Kosmos 65, 93-102. Kozawa, Y., Mishima, H. \& Sakae, T. 1988a: Structure of Sorex (Insectivora) Enamel. The Journal of Nihon University School of Dentistry 30, 120-127.

Kozawa, Y., Sakae, T., Mishima, H., Barckhaus, R.H., Krefting, E.R., Schmidt, P.F. \& Höhling, H.J. 1988b: Electron-microscopic and microprobe analyses on the pigmented and unpigmented enamel of Sorex (Insectivora). Histochemistry 90, 61-65.

Lafuente, B., Downs, R.T., Yang, H. \& Stone, N. 2015: The power of databases: the RRUFF project. In Armbruster, T. \& Danisi, R.M. (eds): Highlights in Mineralogical Crystallography, 1-30. Walter de Gruyter $\underline{\mathrm{GmbH}}$, Berlin, BER.

Lloyd, G.E. 1987: Atomic number and crystallographic contrast images with the SEM: a review of backscattered electron techniques. Mineralogical Magazine 51, 3-19.

Lowater, F. \& Murray, M.M. 1937: CX. Chemical composition of teeth V. spectrographic analysis. Biochemical Journal 31, 837-841.

Luckett, W. P., \& Hartenberger, J. L. 1985: Evolutionary relationships among Rodents. Springer, Boston. Mao, F., Wang, Y. \& Meng, J. 2015: A Systematic Study on Tooth Enamel Microstructures of Lambdopsalis bulla (Multituberculate, Mammalia) Implications for Multituberculate Biology and Phylogeny. Plos one 10: e0128243.

Miles, A. E. W. 1963: Pigmented enamel. Proceedings of the Royal Society of Medicine-London 56, 918$\underline{920 .}$

Mizota, M. \& Maeda, Y. 1986: Magnetite in the radular teeth of chitons. Hyperfine Interactions 29, 14231426.

Moya-Costa, R., Cuenca-Bescós, G., Bauluz, B. \& Rofes, J. 2018: Structure and composition of tooth enamel in quaternary soricines (Mammalia). Quaternary International 481, 52-60. 
Okazaki, M. 1991: Chapter 3.5. Crystallographic Behavior of Iron and Magnesium in Hydroxyapatite Crystals. In Suga, S. \& Nakahara, H. (eds): Mechanisms an Phylogeny of Mineralization in Biological Systems, 309-313. Springer-Verlag, Tokio, TYO.

Reumer J. W. F. 1984: Ruscinian and early Pleistocene Soricidae (Insectivora, Mammalia) from Tegelen (The Netherlands) and Hungary. Scripta Geologica 73, 1-173.

Reumer, J. W. F. 1998: A classification of the fossil and recent shrews. In Wojik, J.M. \& Wolsan, M. (eds.): Evolution of Shrews, 5-22. Polish Academy of Science, Warsaw, VA.

Rofes J. \& Cuenca-Bescós G. 2009a: First record of Beremendia fissidens (Mammalia, Soricidae) in the Pleistocene of the Iberian Peninsula, with a review of the biostratigraphy, biogeography and palaeoecology of the species. Comptes Rendus Palevol 8, 21-37.

Rofes, J., Cuenca-Bescós, G., 2009b: A new genus of red-toothed shrew (Mammalia, Soricidae) from the Early Pleistocene of Gran Dolina (Atapuerca, Burgos, Spain), and a Phylogenetic approach to the Euroasiatic Soricinae. Zoological Journal of the Linnean Society 155, 904-925.

Rzebik-Kowalska B. 2009: Biodiversity of Polish fossil insectivores (Erinaceomorpha, Soricomorpha, Insectivora, Mammalia) compared to the European and global faunas. Polish Academy of Sciences, Kraków.

Saunders, M., Kong, C., Shaw, J., Macey, D. \& Clode, P. 2009: Characterization of biominerals in the radula teeth of the chiton, Acanthopleura hirtosa. Journal of Structural Biology 167, 277-277.

Schofield, R., Niedbala, J., Nesson, M., Tao, Y., Shokes, J., Scott, R. \& Latimer, M. 2009: Br-rich tips of calcified crab claws are less hard but more fracture resistant: A comparison of mineralized and heavyelement biological materials. Journal of Structural Biology 166, 272-287.

Smith, T. \& Codrea, V. 2012: Red Iron-Pigmented Tooth Enamel in a Multituberculate Mammal from the Late Cretaceous Transylvanian "Hateg Island". Plos One 10, e0132550.

Söderlund, E., Dannelid, E. \& Rowcliffe, D.J. 1992: On the hardness of pigmented an unpigmented enamel in teeth of shrews of the genera Sorex and Crocidura (Mammalia, Soricidae). Zeitschrift für Säugetierkunde 57, 321-329.

Strait, S. \& Smith, S. 2006: Elemental analysis of soricine enamel: pigmentation variation and distribution in molars of Blarina brevicauda. Journal of Mammalogy 87, 700-705. 
Suga, S., Taki, Y. \& Ogawa, M. 1992: Iron in the enameloid of perciform fish. Journal of Dental Research 71, 1316-1325.

Suzuki, Y., Kopp, R., Kogure, T., Suga, A., Takai, K., Tsuchida, S., Ozaki, N., Endo, K., Hashimoto, J., Kato, Y., Mizota, C., Hirata, T., Chiba, H., Nealson, K., Horikoshi, K. \& Kirschvink, J. 2006: Sclerite formation in the hydrothermal-vent "scaly-foot" gastropod - possible control of iron sulfide biomineralization by the animal. Earth and Planetary Science Letters 242, 39-50.

Tompsett, S.L. 1935: LV. The copper and "inorganic" iron contents of human tissues. Biochemical Journal $\underline{29,480-486 .}$

Ungar, P.S. 2010: Mammal Teeth. Origin Evolution and Diversity. John Hopkins University Press, Baltimore.

Vogel, P. 1984: Verteilung des roten Zahnschmelzes im Gebiss der Soricidae (Mammalia, Insectivora. Revue Suisse de Zoologie 91, 699-708.

Wang, C., Li, Q., Wang, S., Qu, S. \& Wang, X. 2014: Microstructure and self-sharpening of the magnetite cap in chiton tooth. Materials Science \& Engineering C-Materials For Biological Applications 37, 1-8. Wen, X. \& Paine, M.L. 2013: Iron Deposition and Ferritin Heavy Chain (Fth). Localization in Rodent Teeth. BioMed Central Research Notes 6, 1-11.

Williams, A-M.M. \& Siegele, R. 2014: Iron deposition in modern and archaeological teeth. Nuclear Instruments and Methods in Physics Research B 335, 19-23.

Yao, H., Dao, M., Imholt, T., Huang, J., Wheeler, K., Bonilla, A., Suresh, S. \& Ortiz, C. 2010: Protection mechanisms of the iron-plated armor of a deep-sea hydrothermal vent gastropod. Proceedings of the National Academy of Sciences of the United States of America 107, 987-992.

Akersten, W. A., H. A. Lowenstam, A. Walker \& A. R. Biknevicious 2001: Composition, genesis, and function of shrew tooth "pigmentation". In R. Harrison \& J. R. Stark (eds): Sixth International Congress of Vertebrate Morphology, 201, Journal of Morphology.

Akersten, W. A., H. A. Lowenstam, A. Walker, W. Traub \& R. Biknevicious 2002: How and why do some shrews have red teeth? Journal of Vertebrate Paleontology, 22, 31 A.

Anderson, M. A.\& B. T. Miller 2011: Early Iron Deposition in Teeth of the Streamside Salamander, Ambystoma barbouri. Journal of Herpetology, 45, 336-338. 
Banfield, J. F., S. A. Welch, H. Z. Zhang, T. T. Ebert \& R. L. Penn 2000: Aggregation-based crystal growth and microstructure development in natural iron oxyhydroxide biomineralization products. Science, 289, 751-754.

Bauluz, B., J. M. Gasca, M. Moreno-Azanza \& J. I. Canudo 2014: Unusual replacement of biogenic apatite by aluminium phosphate phases in dinosaur teeth from the Early Cretaceous of Spain. Lethaia, $47,556-566$.

Botka, D. \& L. Meszaros 2014: Beremendia (Mammalia, Soricidae) remains from the late Early Pleistocene Somssich Hill 2 locality (Southern Hungary) and their taxonomic, biostratigraphical, palaeoecological and palaeobiogeographical relations. Fragmenta Palaeontologica Hungarica, 31, 83115

Boyde, A. 1964: The Structure and Development of Mammalian Enamel, 228 pp., University of London, United Kingdom.

Gampana, I., A. Benito-Calvo, A. Perez-Gonzalez, A. Ortega, J. de Castro \& E. Carbonell 2017: Pleistocene sedimentary facies of the Gran Dolina archaoo-paleoanthropological site (Sierra de Atapuerca, Burgos, Spain). Quaternary International, 433, 68-84.

Guenca-Bescós, G., H. A. Blain, J. Rofes, I. Lozano-Fernandez, J. M. López-Garcia, M. Duval, J. Galán \&. C. Núnez Lahuerta 2015: Comparing two different Early Pleistocene microfaunal sequences from the caves of Atapuerca, Sima del Elefante and Gran Dolina (Spain): Biochronological implications and significance of the Jaramillo subchron. Quaternary International, 389, 148-158.

Guenca Bescós, G., H. A. Blain, J. Rofes, J. M. López-García, 1. Lozano-Fernandez, d. Galán \& C. Núnez-Lahuerta 2016: Updated Atapuerca biostratigraphy: Small-mammal distribution and its implications for the biochronology of the Quaternary in Spain. Comptes Rendus Palevol, 15, 621-634.

Guenca-Bescós, G. \& J.Rofes 2007: Firstevidence of poisonous shrews with an envenomation apparatus. Naturwissenschaften, 94, 113-116.

Dannelid, E. 1994: Comparison of pigment and other dental characters of eastern paleoartic Sorex Aammalia: Soricidae). In J.F. Merrit, J. L. J. Kirkland \& R. K. Rose (eds): Advances in the Biology of Shrews, Vol. 18, 217-231, Carnegie Museum of Natural History, Pittsburgh.

Dumont, M., T. Tutken, A. Kostka, M. J. Duarte \& S. Borodin 2014: Structural and functional characterization of enamel pigmentation in shrews. Journal of Structural Biology, 186, 38-48.

Dötsch, V. C. \& W. v. Koenigswald 1978: Zur Rotfärbung von Soricidenzähnen. Zeitschrift für Säugetierkunde, 43, 65-70.

Furió, M., J. Agusti, A. Mouskhelishvili, O. Sanisidro \& A. Santos-Cubedo 2010: The paleobiology of the extinct venomous shrew Beremendia (Soricidae, Insectivora, Mammalia) in relation to the geology and paleoenvironment of Dmanisi (Early Pleistocene, Georgia). Journal of Vertebrate Paleontology, 30, 928 942

García-Alix, A., R. Minwer-Barakat, E. M. Suarez, M. Freudenthal \& A. D. Huertas 2013: Cinnabar mineralization in fossil small mammal romains as a consequence of diagenetic processes. Lethaia, 46, 1-6. 
Gomes Rodrigues, H. 2015: The great variety of dental structures and dynamics in rodents: new insights into their ecological diversity. In P. G. Cox \& L. Hautier (eds): Evolution of the Rodents: Advances in Phylogeny, Functional Morphology and Development, 424-447, Cambridge University Press.

Gordon, L. M., M. J. Cohen, K. W. MacRenaris, J. D. Pasteris, T. Seda \& D. Joester 2015: Amorphous intergranular phases control the properties of rodent tooth enamel. Science, 347, 746-750.

Heap, P. F., B. K. B. Berkovitz, M. S. Gillett \& D. W. Thompson 1983: An analytical ultrastructurat-study of the iron-rich sureface-layer in rat-incisor enamel. Archives of Oral Biology, 28, 195-200.

Hoek Ostende, L., K. Doukas \& J. W. F. Reumer 2005: The Fossil Record of the Eurasian Neogene insectivores (Erinaceomorpha, Soricomorpha, Mammalia), part I. Vol. Speciall Issue 5, Scripta Geologica, Leiden.

darvinen, E., K. Valimaki, M. Pummila, I. Thesleff \& J. Jernvall 2008: The taming of the shrew milk teeth. Evolution \& Development, 10, 477-486.

Koenigswald, W. v. 1980: Schmelzmuster und Morphologie in den Molaren der Arvicolidae (Rodontia). Abhandlungon der Senckenbergischen natuiforschenden Gesellschaft, 539, 1-129.

1997: Evolutionary trends in the differentiation of mammalian enamel ultrastructure. In W. V. Koenigswald \& P. M. Sander (eds): Tooth enamel microstructure, 203-235, Balkema, Rotterdan.

Koonigswald, W. v. \&.P. M. Sander 1997: Glossary of torms used for onamol microstructures. In W. v. S. Koenigswald, P. M. (ed): Tooth enamel microstructure, 267-280, Balkema, Rotterdam.

Korvenkontio, V.A. 1934: Mikroskopische Untersuchungen an Nagerincisiven unter Hinweis auf die Schmelzstruktur der Backenzahno. Histologischphyletischo Studio. Annales Zoologici Sociotatis Zoologicae-botanicae Fennice Vanamo, 2, 1-280.

Kowalski, K. \& K. Duk 2016: Kopalne ssaki jadowite z nadrzędu Eulipotyphla. Kosmos, 65, 93-102.

Kozawa, Y., H. Mishima \& Y. Saka 1988: Structure of Sorex (nnsectivora) Enamel. The Journal of Nihon University School of Dentistry, 30, 120-127.

Kozawa, Y., T. Sakae, H. Mishima, R. H. Barckhaus, E. R. Krefting, P. F. Schmidt \& H. J. Hohling 1988: Electron-microscopic and microprobe analyses on the pigmented and unpigmented enamel of Sorex (Insectivora). Histochemistry, 90, 61-65.

Lafuente, B., R. T. Downs, H. Yang \& N. Stone 2015: The power of databases: the RRUFF project. In T. Armbruster \& R. M. Danisi (eds): Highlights in Mineralogieal Crystallography, 1-30, Berlin.

Hloyd, G. E. 1987: Atomic-number and crystallographic contrast images with the SEM - A review of Backscattered Electron Techniques. Mineralogical Magazine, 51, 3-19.

Lowater, F.\& M. M. Murray 1937: Chemical composition of teeth V. Spectrographic analysis. Biochemical Journal, 31, 837-841.

Luckett, W. P. 1979: Evolutionary Relationships among Hystricomorphous Rodents. Evidence of the Fetal Membranes and Placenta. Anatomical Record, 193,607-607. 
Mao, F. Y., Y. Q. Wang \& J. Meng 2015: A Systematic Study on Tooth Enamel Microstructures of Lambdopsalis bulla (Multituberculate, Mammalia) - Implications for Multituberculate Biology and Phylogeny. Plos One, 10.

Miles, A. E. W. 1963: Pigmented enamel. Proceedings of the Royal Society of MedicineLondon, 56, 918-920.

Aizota, M. \& Y. Maeda 1986: Magnetite in the radular teeth of chitons. Hyperfine Interactions, 29, $1423-$ 1426.

Moya-Costa, R., G. Cuenca-Bescós, B. Bauluz \& J. Rofes 2018: Structure and composition of tooth enamel in quaternary soricines (Mammalia). Quaternary International, 481, 52-60.

Okazaki, M. 1991: Crystallographic Behavior of Iron and Magnesium in Hydroxyapatite Crystals. In S. Suga \& H. Nakahara (eds): Mechanisms and Phylogeny of Mineralization in Biological Systems, 309313 , Springer-Verlag, Tokio.

Reumer, J. W. F. 1984: Ruscinian and early Pleistocene Soricidae (Insectivora, Mammalia) from Tegolen (The Netherlands) and Hungary. Scripta Geologica, 73, 1-173.

1998: A classification of the fossil and recent shrews. In J. M. Wojik \& M. Wolsan (eds): Evolution of Shrews, 5-22, Mammal Research Institute, Polish Academy of Science, Bialowieza.

Rofes, J.\& G. Cuenca-Bescos 2009a: A new genus of red-toothed shrow (Mammalia, Soricidae) from the Early Pleistocene of Gran Dolina (Atapuerca, Burgos, Spain), and a phylogenetic approach to the Eurasiatic Soricinae. Zoological Journal of the Linnean Society, 155, 904-925.

Rofes, J.\& G. Cuenca-Bescós 2009b: First record of Beremendia fissidens (Mammalia, Soricidae) in the Pleistocene of the Iberian Peninsula, with a review of the biostratigraphy, biogeography and palaeoecology of the species. Comptes Rendus Palevol, 8, 21-37.

Rzebik-Kowalska, B. 2009: Biodiversity of Polish fossill insectivores (Erinaceomorpha, Soricomorpha, Insectivora, Mammalia) compared to the European and global faunas. Institute of Systematics and Evolution of Animals, Polish Academy of Sciences, Kraków.

Saunders, M., C. Kong, J. Shaw, D. Macey \& P. Clode 2009: Characterization of biominerals in the radula teeth of the chiton, Acanthopleura hirtosa (vol 167, pg 55, 2009). Journal of Structural Biology, 167, 277. 277.

Schofield, R., J. Niedbala, M. Nesson, Y. Tao, J. Shokes, R. Scott \& M. Latimer 2009: Br-rich tips of calcified crab claws are less hard but more fracture resistant: A comparison of mineralized and heavyelement biological materials. Journal of Structural Biology, 166, 272-287.

Smith, T.\& V. Codrea 2015: Red Iron-Pigmented Tooth Enamel in a Multituberculate Mammal from the Late Cretaceous Transylvanian "Hateg Istand". Plos One, 10.

Strait, S. G. \& S. G. Smith 2006: Elemental analysis of Soricine enamel: Pigmentation variation and distribution in molars of Blarina brevicauda. Journal of Mammalogy, 87, 700-705.

Suga, S., Y. Taki \& M. Ogawa 1992: Iron in the enameloid of perciform fish. Journal of Dental Research, 71, 1316-1325. 
Suzuki, Y., R. Kopp, T. Kogure, A. Suga, K. Takai, S. Tsuchida, N. Ozaki, K. Endo, J. Hashimoto, Y. Kato, C. Mizota, T. Hirata, H. Chiba, K. Nealson, K. Horikoshi \& J. Kirschvink 2006: Sclerite formation in the hydrothermat-vent "scaly-foot" gastropod-possible control of iron sulfide biomineralization by the animal. Earth and Planetary Science Letters, 242, 39-50.

Söderlund, E., E. Dannelid \& D. J. Rowcliffe 1992: On the Hardness of Pigmented and Unpigmented Enamel in Teeth of Shrews of the Genera Sorex and Grocidura (Mammalia, Soricidae). Zeitschrift Fur Saugetierkunde-International Journal of Mammalian Biology, 57, 321-329.

Tompsett, S. L. 1935: The copper and "inorganic" iron contents of human tissues. Biochemical Journal, $29,480-486$.

Ungar, P. S. 2010: Mammal Teeth. Origin Evolution and Diversity. John Hopkins University Press, Baltimore.

Vogel, P. 1984: Distribution of red enamel on the teeth of Soricidae (Mammalia, Insectivora). Revue Suisse De Zoologie, 91, 699-708.

Von Koenigswald, W., D.C. Kalthoff \&.G.M. Semprebon 2010: The microstructure of enamel, dentine and cementum in advanced Taeniodonta (Mammalia) with comments on their dietary adaptations. Journal of Vertebrate Paleontology, 30, 1797-1804.

Wang, C., Q. Li, S. Wang, S.Qu \& X.Wang 2014: Microstructure and self-sharponing of the magnetite sap in chiton tooth. Materials Science \& Engineering C-Materials For Biological Applications, 37, 1-8.

Wen, X. \& M. L. Paine 2013: Iron Deposition and Ferritin Heavy Chain (Fth). Localization in Rodent Teeth. BioMed Central Research Notes, 6, 1-11.

Williams, A. M. M. \& R. Siegele 2014: Iron deposition in modern and archaeological teeth. Nuclear Instruments \& Methods in Physics Research Section B-Beam Interactions With Materials and Atoms, 335, 19-23.

Yao, H., M. Dao, T. Imholt, J. Huang, K. Wheeler, A. Bonilla, S. Suresh \& C. Ortiz 2010: Protection mechanisms of the iron-plated armor of a deep-sea hydrothermal vent gastropod. Proceedings of the National Academy of Sciences of the United States of America, 107, 987-992. 

discontinuous lines indicate the orientation of the sections observed in SEM.

Figure 2. Combination of BSE images of the sections of the recent $S$. coronatus incisors, microphotographs, enlargementsdetails, schemes of structure and results of the Fe quantities with respect to $\mathrm{Fe}+\mathrm{Ca}+\mathrm{P}$. A-K are referredpertain -to the transverse section S1. A. General compositional image, division of transverse section of $S$. coronatus and location of the detailsenlargements. B. Microphotograph of the section and division of enamelwith enamel layers labelled. C. DetailEnlargement of the lower part of the bend in the lower part of the tooth. D. DetailEnlargement of the labial part and location of analyses. E. DetailEnlargement of the end of the enamel in the upper part of the tooth. F. DetailEnlargement of L1. G. DetailEnlargement of L2. H. DetailEnlargement of L3. I, J, K. Results of Fe in the analyses marked in C and D. L- Q are referredpertain to the longitudinal section. L. General compositional image of the longitudinal section of $S$. coronatus, division of enamel and location of details.enlargements. M. DetailEnlargement of the tip of the tooth and location of showing location of analyses-location. N. Microphotohgraph of the tip of the section and superimposition of the division of enamel. O. DetailEnlargement of the prisms with open sheaths in the enamel close to the root. P. Results of the analyses shown in M. Q. Composition of detailed compositional images of the enamel and-division of enamel. In the analyses each dot drawn is a spot of analysisis an analysis point.

Figure 3. Tangential/transverse section of Crocidura (S3). A. General compositional image and division of enamel. B. Microphotograph of the section and division of the enamel. C. DetailEnlargement of the different layers of the enamel layers from area shown in A.

Figure 4. General view of BSE images of sections of the fossil soricids B. fissidens and D. glyphodon, microphotographs, sketch of the division of enamel, enlargementetetails and results of Fe with respect to $\mathrm{Fe}+\mathrm{Ca}+\mathrm{P} . \mathrm{A}-\mathrm{F}$ are referredpertain to the transverse section of $B$. fissidens (S4). A. Composition of BSE images of a general view of the section, division of enamel and location of the enlargementdetails. B. Microphotograph of the section and division of enamel. C. EnlargementDetail of the part with L3. D. 


\section{EnlargementDetail of pigmentedof pigmented enamel with the division and location of analyses. E.}

Results of Fe in the-analyses of I-I'. F. Results of Fe in the-analyses of II-II'.G-M are referredpertain to the D. glyphodonlongitudinal section of D. glyphodon (S5a). G. General BSE view of the section of the tip with the division of enamel and the location_of of the detailsenlargements. H. Microphotograph of the section and division of enamel. I. EnlargementDetail of the pigmented enamel with the division and location of the analyses. J. Enlargement Detait-of $\mathrm{L} 2$ in the pigmented enamel ${ }_{i ;} ;$ white parts have Fe. K. DetailEnlargement of the worn tip with wear. L. Enlargement Detail-of the worn enamel. M. Results of the analyses. In the analyses each dot drawndotpoint is an-spot of analysis point.

Figure 5. General view of BSE images of two of the sections (S5 b and S6) of the fossil soricid $D$. glyphodon, microphotographs, sketch of the division of enamel, enlargementetetails and results of Fe with respect to $\mathrm{Fe}+\mathrm{Ca}+\mathrm{P}$. A-H are referredpertain to the longitudinal section S5b. A. Composition of BSE images of a general view, division of enamel and location of detailsenlargements. B. Microphotograph of the tip if of the tooth with the division of enamel superimposed uponto the colours of the tooth. C. BSE image of the tip and locations of the-analyses. D. EnlargementPetail of the labial part of pigmented enamel and division. E. Enlargement Detail-of the tip of the incisor and division of enamel. F. EnlargementDetail of L2 in the tip and locations of the analyses. G. Results of Fe in the linear analyses across the enamel. H. Results of $\mathrm{Fe}$ in the point analyses of prisms and IPM indicated in F. I-O are referred-pertain to the transverse section S6. I. Composition of BSE of a general view, division of enamel and locations of details-enlargements and analyses. J. Microphotograph of the section showing enamel divisions-with the division of enamel. K. EnlargementDetail of L1, in the upper part of the tooth. L. EnlargementBetail of the pigmented enamel and enamel divisions-of enamel. M. EnlargementBetait of prisms in the-Fe-rich phaseenamelenamel rich in Fo. $\mathrm{N}_{-}$. Results of-Fe in the-analyses of I-I'. O. Results of Fe in the analyses of II-II'. In the analyses each dot_drawn is an spot of analysis point.

Figure 6. Microphotograph, general view, compositional images, schemes of the structure and Fe analyses of the longitudinal/tangential section of the recent rodent Terricola (S7). A. Microphotograph of the section and drawing of dentine and enamel. B. General compositional image, division of enamel and location of enlargementetails. C. EnlargementDotail of the enamel in the pigmented part and location of 
the enlargement detail of L2. D. EnlargementDetail of L2 and location of analyses. E. EnlargementDetail of the enamel in the non-pigmented part of the tooth. F. EnlargementDetail of the labial part of the tooth, near the transition from pigmented to non-pigmented enamel. G. Fe analyses across the enamel in the points marked in $\mathrm{D}$. In the analyses each dot-drawn is an spot of analysis point.

Figure 7. General view, compositional images, optical microphotograph, schemes of the structure and Fe analyses of the transverse section of the recent rodent Terricola (S8). A. General compositional image, division of enamel and location of the images of enlargementetetails. B. Microphotograph of the section and location of enamel and dentine. In the embedded surface the pigmentation is visiblecan be observed. C. Enlargement Detail of the enamel in the pigmented part and location of a line of analyses. D. EnlargementDetail of the anterior part and location of spots of analysis_points in the Fe-rich zone. E. EnlargementDetail of the different layers of enamel. F. Results of $\mathrm{Fe}$ in the linear analyses. G. Results of the points analysed in $D$, the highest values being in the white spots irrespective ndependent of the distance to the surface. In the analyses each dot drawn is a spot of analysisis an analysis point.

Figure 8. TEM images of the enamel of Dolinasorex: A. Image of the relation among apatite (Ap) crystals and Fe clusters; two aggregates of apatite are visiblecan be observed divided by a cluster of Fe (femarked by a dotted line). B. HRTEM images of two apatite crystals, one of them cut perpendicular to the $c$ axis and the other parallel to it; and inset with the FFT of one of them. C. HRTEM image of apatite crystals with different orientations. D. HRTEM image of the Fe phase. Some weak planes are visiblecan be observed due to the variable orientation of the particles. E. FFT of the Fe of the Fig. $8 \mathrm{D}$ and interplanar distances. F. FFT of the apatite of the Fig. 8 B and interplanar distances. G. FFT of the apatite of the-Fig. $8 \mathrm{C}$ and interplanar distances.

Figure 9. STEM images showing the different composition and textural relation of the Fe phase (white) and of the apatite (grey-colour) in the enamel of Dolinasorex. A. General view of the relation between the Fe phase and apatite. -Apatite forms aggregates of-big large crystals, and the Fe phase is-surroundsing some of the aggregates and is located among them ${ }_{-;}$B. EnlargementDetail of the nanoparticles that form the Fe phase. Each dot is one crystal and the size is lesssmaller than $1 \mathrm{~nm}$. 
Figure 10. Sketches of the main characteristics of the division of the enamel in the species studied: $S$. coronatus, B. fissidens, D. glyphodon, Terricola and Crocidura. IThere are indicated are the number of divisions, the type of enamel of each one, whetherif or not they have-tubules are present, and the $\mathrm{Fe}$ content.

Figure 11. Example of the size of the areas analysed by point EDS analysis (circles) compared with the size of the enamel prisms of $S$. coronatus and D. glyphodon. Note that the analyses ofin $D$. glyphodon can be performed on a singleonly one element, whereas in S. coronatus this is more difficult. In the image of S. coronatus the difference in the grey of the IPM differs visibly in the layer with Fe (white) fromand without Fe (dark grey-black)-can be observed. 


\section{Table captions}

Table 1. Summary of the main characteristics of the division of enamel in the species studied. In bold the highest quantities of $\mathrm{Fe}$ in each species. 

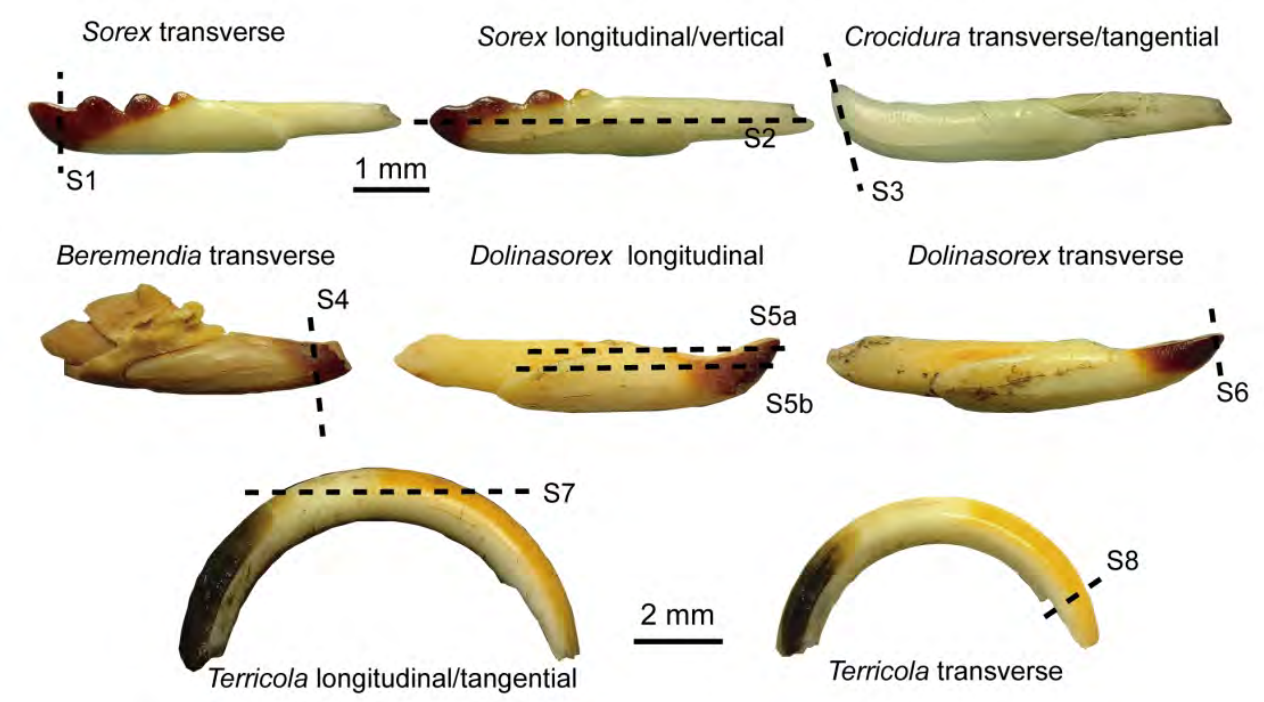

Figure 1. Labial view of the samples studied: the incisors of Eulipotyphla and Rodentia species. The discontinuous lines indicate the orientation of the sections observed in SEM.

$170 \times 93 \mathrm{~mm}(300 \times 300 \mathrm{DPI})$ 

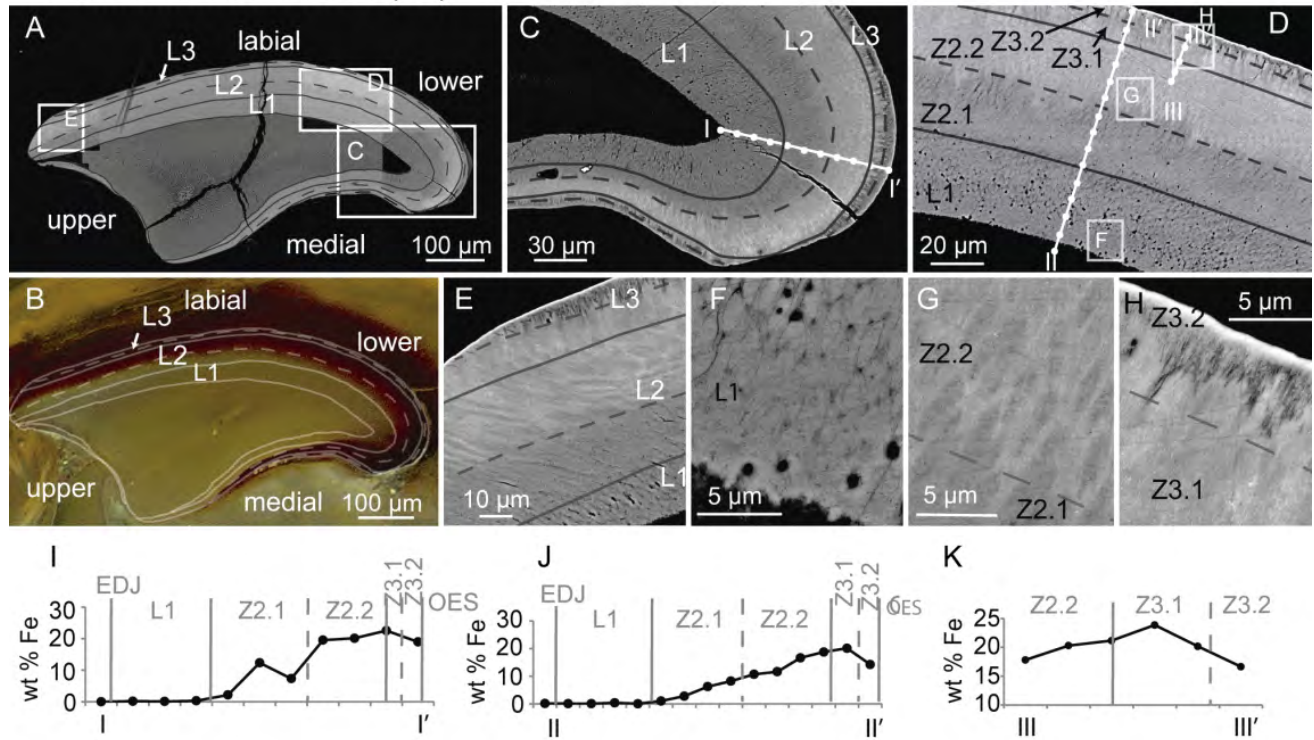

K

S. coronatus longitudinal (S2)
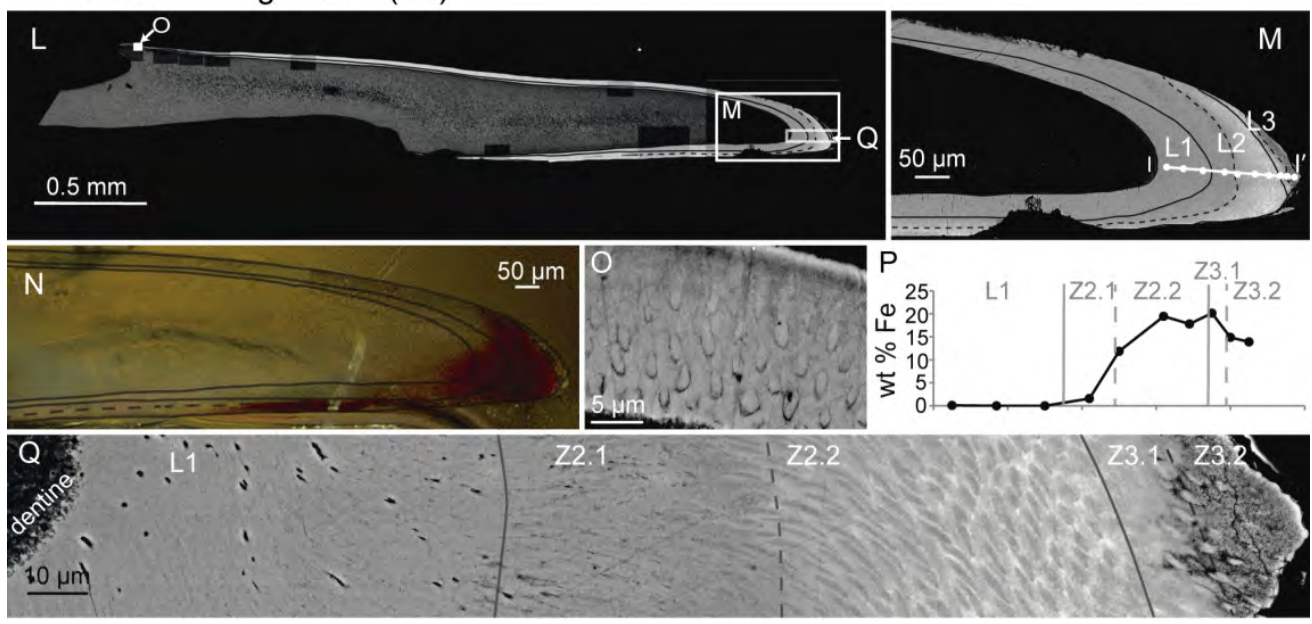

Figure 2. Combination of BSE images of the sections of the recent S. coronatus incisors, microphotographs, enlargements, schemes of structure and results of the Fe quantities with respect to $\mathrm{Fe}+\mathrm{Ca}+\mathrm{P}$. A-K pertain to the transverse section S1. A. General compositional image, division of transverse section of S. coronatus and location of enlargements. B. Microphotograph of the section with enamel layers labelled. C. Enlargement of the lower part of the bend in the lower part of the tooth. D. Enlargement of the labial part and location of analyses. E. Enlargement of the end of the enamel in the upper part of the tooth. F. Enlargement of L1. G. Enlargement of L2. H. Enlargement of L3. I, J, K. Results of Fe analyses marked in C and D. L- Q pertain to the longitudinal section. L. General compositional image of the longitudinal section of S. coronatus, division of enamel and location of enlargements. M. Enlargement of the tip of the tooth showing location of analyses. $\mathrm{N}$. Microphotograph of the tip of the section and superimposition of the division of enamel. O. Enlargement of the prisms with open sheaths in the enamel close to the root. P. Results of the analyses shown in M. Q. Composition of detailed compositional images of the enamel and division of enamel. In the analyses each dot is an analysis point. 
2

3

4

5

6

7

8

9

10

11

12

13

14

15

16

17

18

19

20

21

22

23

24

25

26

27

28

29

30

31

32

33

34

35

36

37

44

45

46

47

48

49

50

51

52

53

54

55

56

57

58

59

60

Lethaia - manuscript copy 

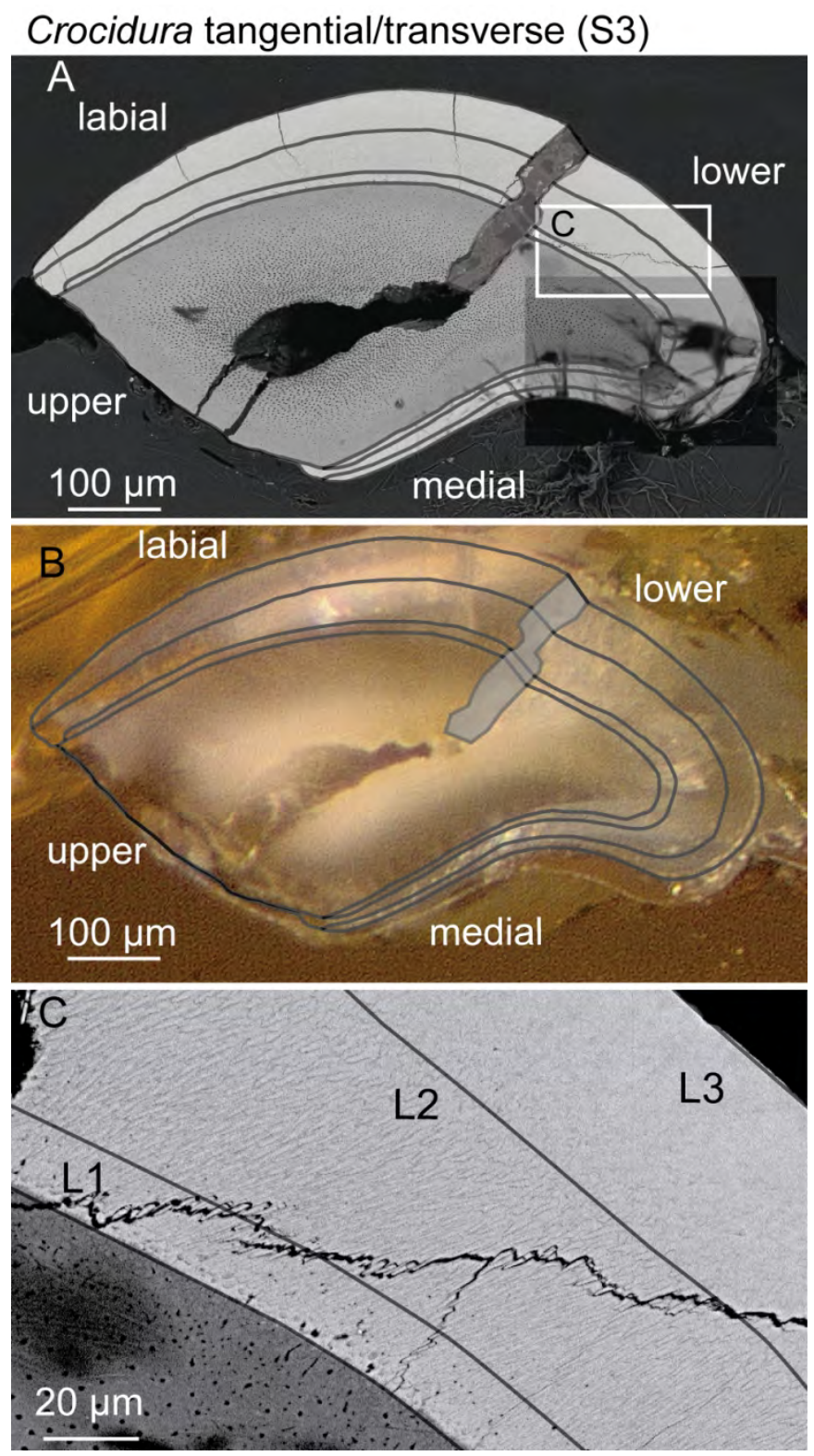

Figure 3. Tangential/transverse section of Crocidura (S3). A. General compositional image and division of enamel. B. Microphotograph of the section and division of the enamel. C. Enlargement of enamel layers from area shown in A.

$79 \times 144 \mathrm{~mm}(300 \times 300 \mathrm{DPI})$ 

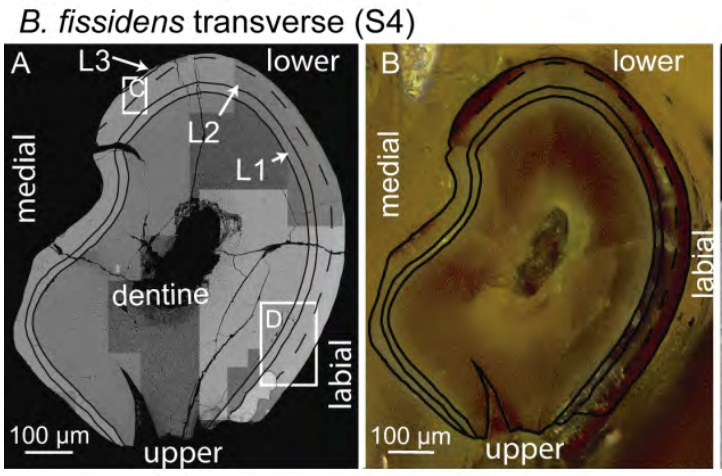

E

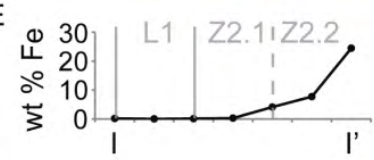

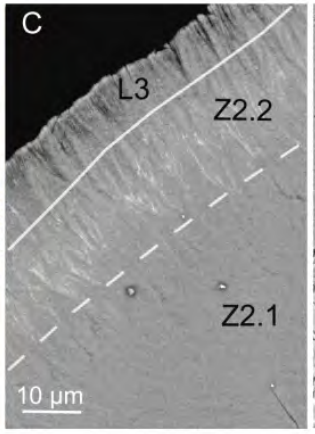
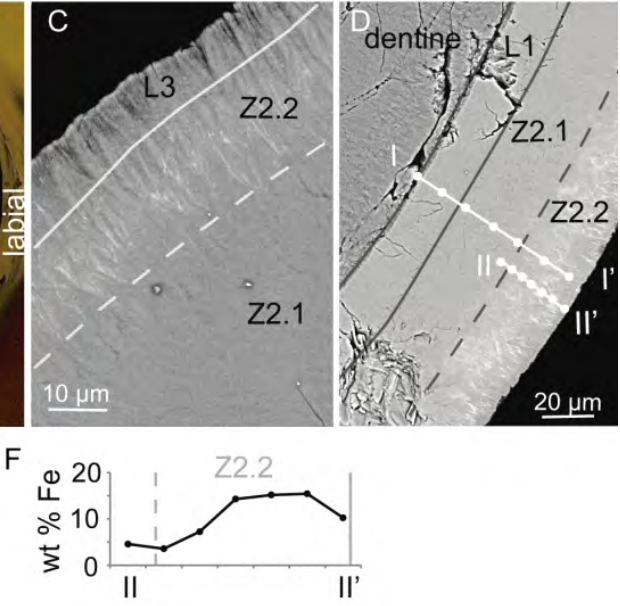

D. glyphodon longitudinal (S5a)
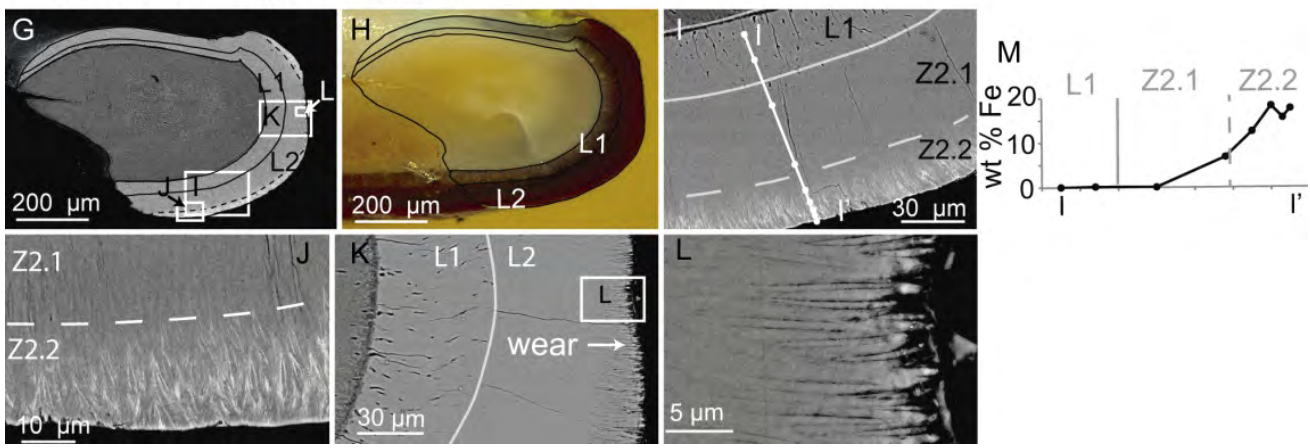

Figure 4. General view of BSE images of sections of the fossil soricids B. fissidens and D. glyphodon, microphotographs, sketch of the division of enamel, enlargements and results of Fe with respect to

$\mathrm{Fe}+\mathrm{Ca}+\mathrm{P}$. A-F pertain to the transverse section of B. fissidens (S4). A. Composition of BSE images of a general view of the section, division of enamel and location of the enlargements. B. Microphotograph of the section and division of enamel. C. Enlargement of the part with L3. D. Enlargement of pigmented enamel with the division and location of analyses. E. Results of Fe analyses of I-I'. F. Results of Fe analyses of IIII'.G-M pertain to the longitudinal section of D. glyphodon (S5a). G. General BSE view of the section of the tip with the division of enamel and location of enlargements. H. Microphotograph of the section and division of enamel. I. Enlargement of the pigmented enamel with the division and location of analyses. J.

Enlargement of L2 in the pigmented enamel; white parts have Fe. K. Enlargement of the worn tip. L. Enlargement of the worn enamel. M. Results of the analyses. In the analyses each dot is an analysis point.

\section{$170 \times 151 \mathrm{~mm}(300 \times 300 \mathrm{DPI})$}




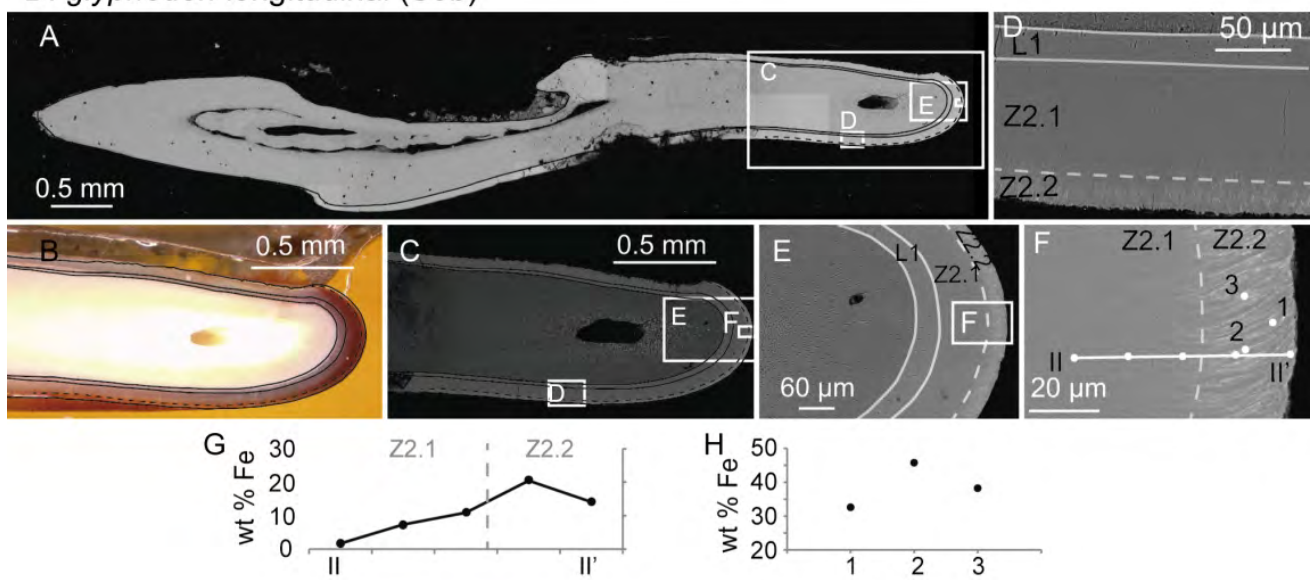

D. glyphodon transverse (S6)
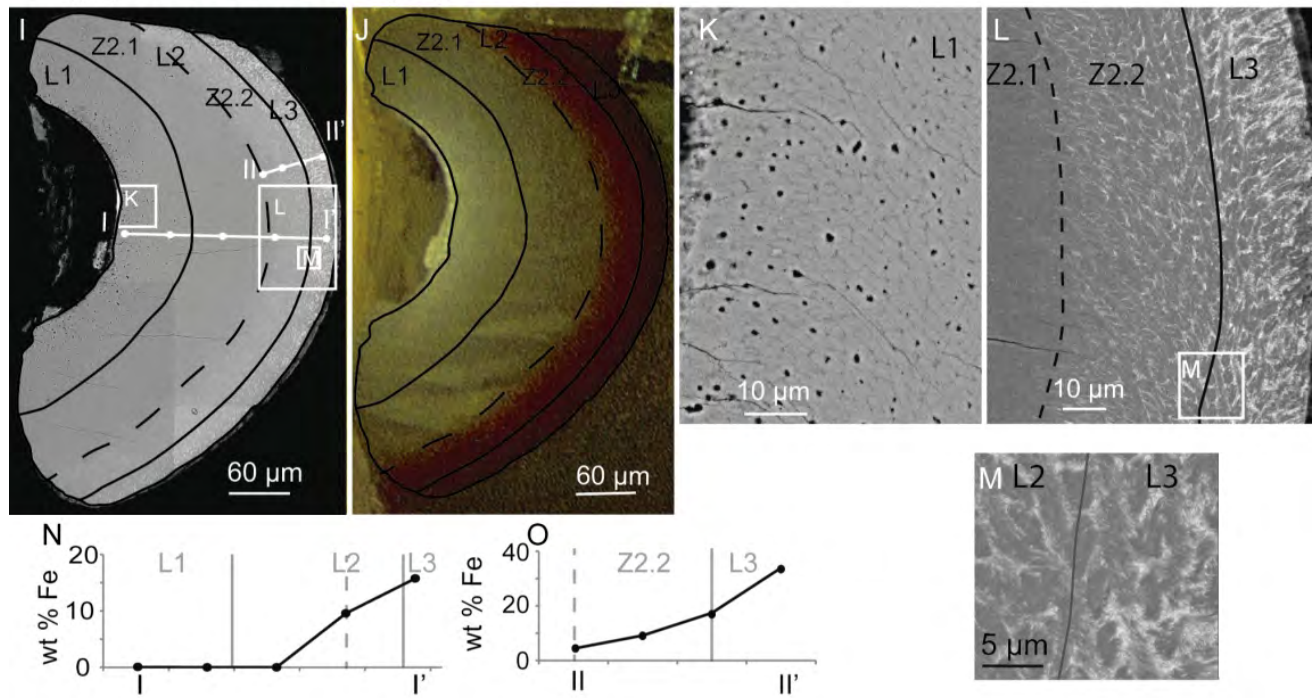

Figure 5. General view of BSE images of two of the sections (S5 b and S6) of the fossil soricid D. glyphodon, microphotographs, sketch of the division of enamel, enlargements and results of Fe with respect to $\mathrm{Fe}+\mathrm{Ca}+\mathrm{P}$. A-H pertain to the longitudinal section S5b. A. Composition of BSE images of a general view, division of enamel and location of enlargements. B. Microphotograph of the tip of the tooth with the division of enamel superimposed upon the colours of the tooth. C. BSE image of the tip and locations of analyses. D. Enlargement of the labial part of pigmented enamel and division. E. Enlargement of the tip of the incisor and division of enamel. F. Enlargement of L2 in the tip and locations of analyses. G. Results of Fe in the linear analyses across the enamel. $\mathrm{H}$. Results of $\mathrm{Fe}$ in the point analyses of prisms and IPM indicated in $\mathrm{F}$. I-O pertain to the transverse section S6. I. Composition of BSE of a general view, division of enamel and locations of enlargements and analyses. J. Microphotograph of the section showing enamel divisions. K.

Enlargement of L1, in the upper part of the tooth. L. Enlargement of the pigmented enamel and enamel divisions. M. Enlargement of Fe-rich enamel. N. Fe analyses of I-I'. O. Fe analyses of II-II'. In the analyses each dot is an analysis point.

$170 \times 185 \mathrm{~mm}(300 \times 300 \mathrm{DPI})$ 
Terricola longitudinal/tangential (S7)

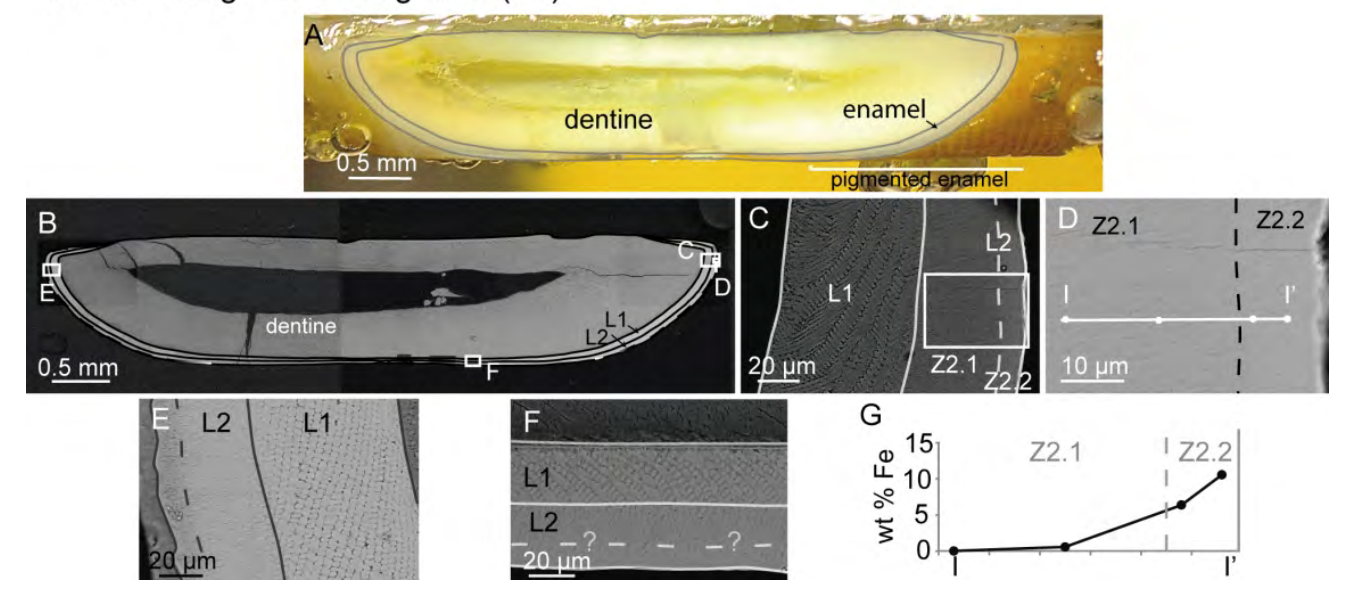

Figure 6. Microphotograph, general view, compositional images, schemes of the structure and Fe analyses of the longitudinal/tangential section of the recent rodent Terricola (S7). A. Microphotograph of the section and drawing of dentine and enamel. B. General compositional image, division of enamel and location of enlargements. C. Enlargement of the enamel in the pigmented part and location of the enlargement of L2. D. Enlargement of L2 and location of analyses. E. Enlargement of the enamel in the non-pigmented part of the tooth. F. Enlargement of the labial part of the tooth, near the transition from pigmented to nonpigmented enamel. G. Fe analyses across the enamel in the points marked in D. In the analyses each dot is an analysis point.

$170 \times 81 \mathrm{~mm}(300 \times 300 \mathrm{DPI})$ 


\section{Terricola transverse (S8)}
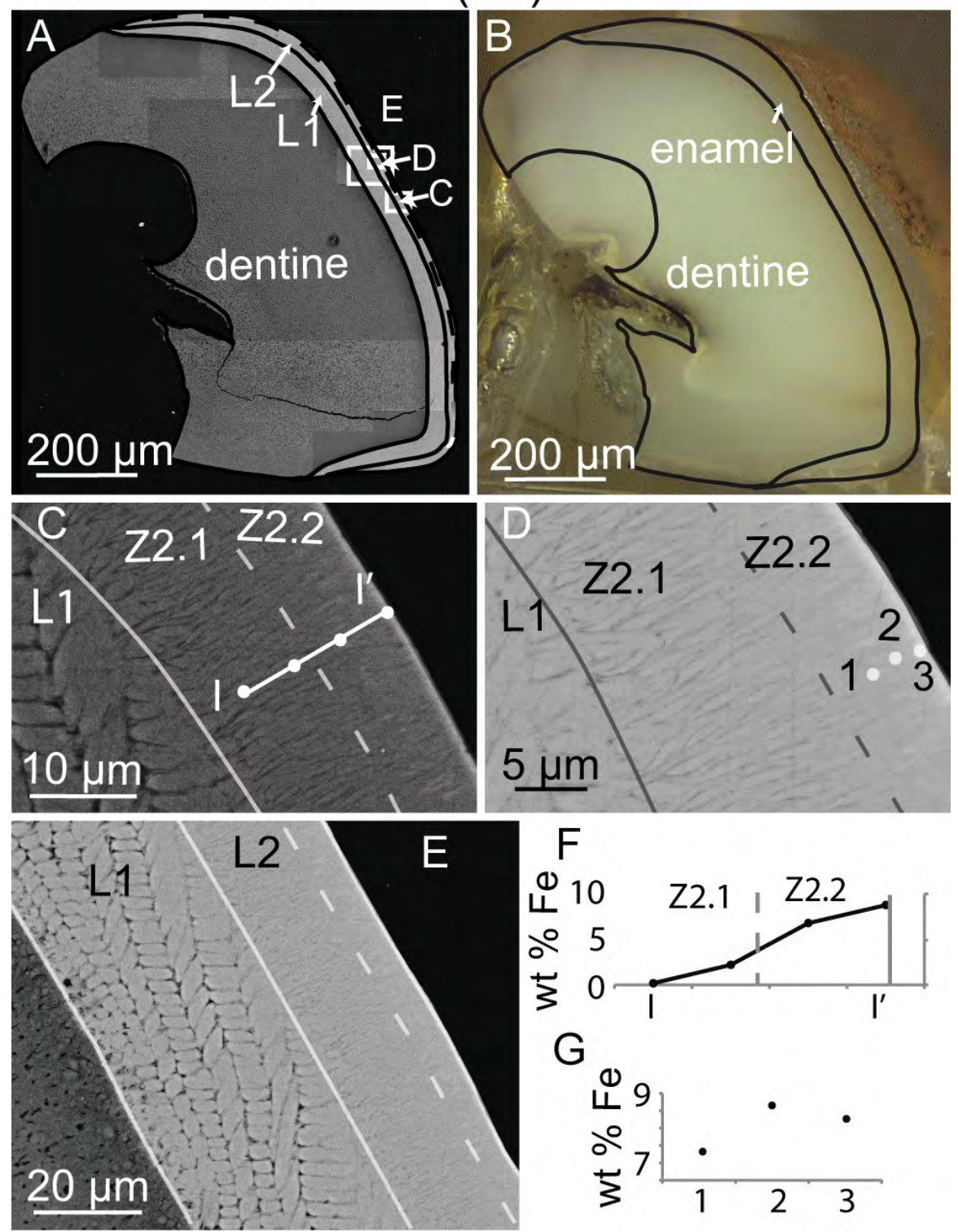

Figure 7. General view, compositional images, optical microphotograph, schemes of the structure and Fe analyses of the transverse section of the recent rodent Terricola (S8). A. General compositional image, division of enamel and location of enlargements. B. Microphotograph of the section and location of enamel and dentine. In the embedded surface the pigmentation is visible. C. Enlargement of the enamel in the pigmented part and location of a line of analyses. D. Enlargement of the anterior part and location of analysis points in the Fe-rich zone. E. Enlargement of the different layers of enamel. F. Results of Fe in the linear analyses. G. Results of the points analysed in D, the highest values being in the white spots irrespective of the distance to the surface. In the analyses each dot is an analysis point.

\section{$82 \times 112 \mathrm{~mm}(300 \times 300 \mathrm{DPI})$}



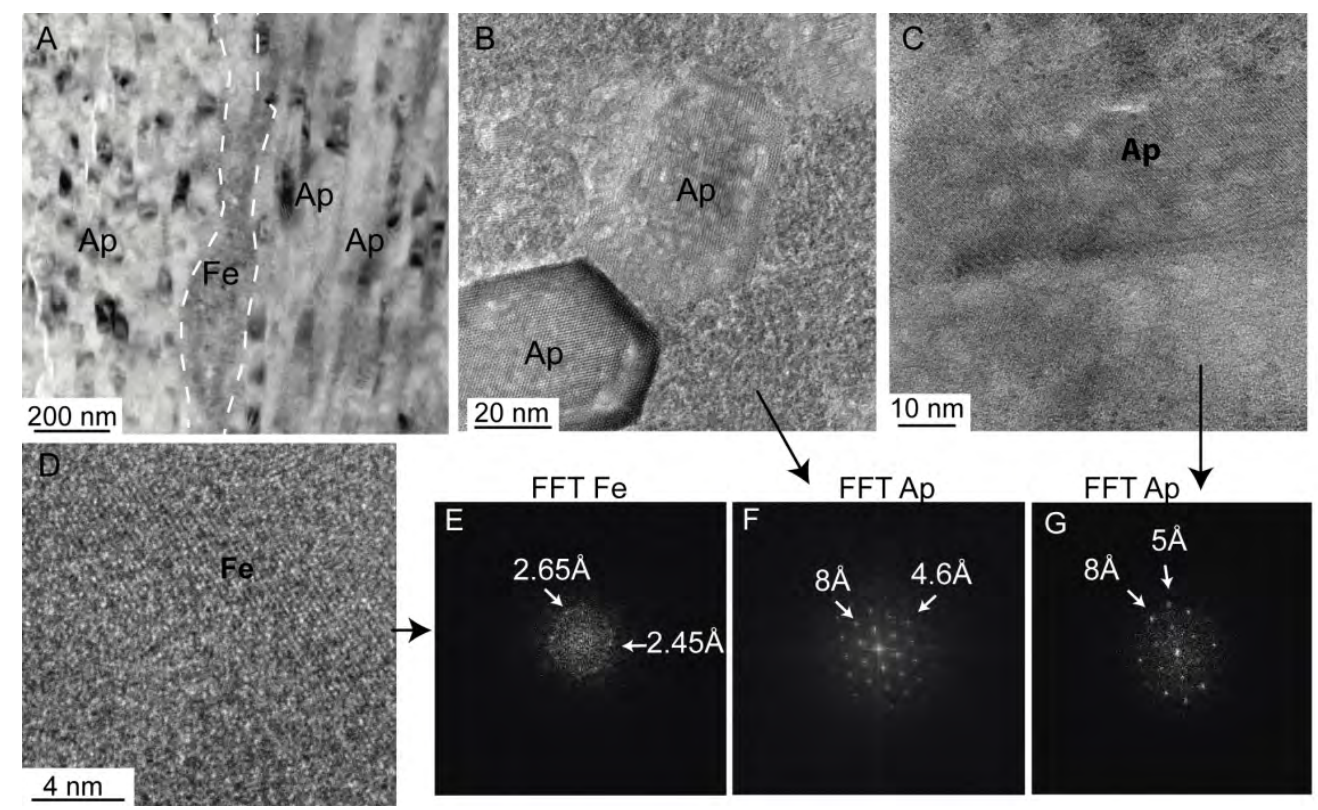

Figure 8. TEM images of the enamel of Dolinasorex: A. Image of the relation among apatite (Ap) crystals and Fe clusters; two aggregates of apatite are visible divided by a cluster of Fe (marked by a dotted line). B. HRTEM images of two apatite crystals, one of them cut perpendicular to the c axis and the other parallel to it; and inset with the FFT of one of them. C. HRTEM image of apatite crystals with different orientations. D. HRTEM image of the Fe phase. Some weak planes are visible due to the variable orientation of the particles.

E. FFT of the Fe of Fig. 8 D and interplanar distances. F. FFT of the apatite of Fig. 8 B and interplanar distances. G. FFT of the apatite of Fig. $8 \mathrm{C}$ and interplanar distances.

$$
170 \times 103 \mathrm{~mm}(300 \times 300 \mathrm{DPI})
$$



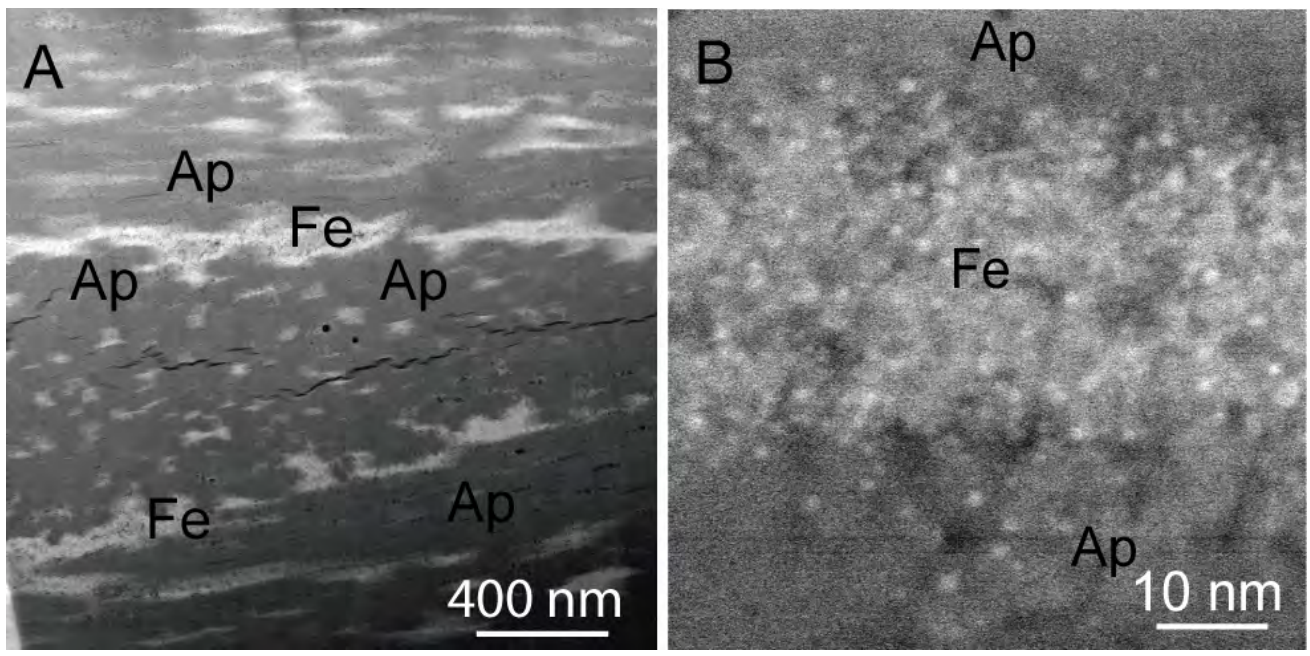

Figure 9. STEM images showing the different composition and textural relation of the Fe phase (white) and the apatite (grey) in the enamel of Dolinasorex. A. General view of the relation between the Fe phase and apatite. Apatite forms aggregates of large crystals, and the Fe phase surrounds some of the aggregates and is located among them. B. Enlargement of the nanoparticles that form the Fe phase. Each dot is one crystal and the size is less than $1 \mathrm{~nm}$.

$83 \times 40 \mathrm{~mm}(300 \times 300 \mathrm{DPI})$ 


\author{
S. coronatus
}

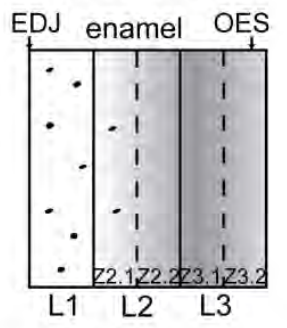

B. fissidens

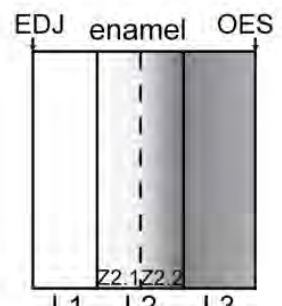

Crocidura

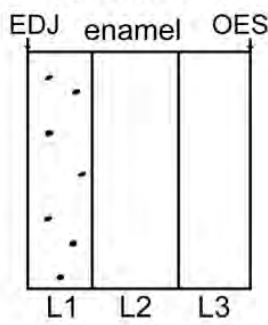

D. glyphodon

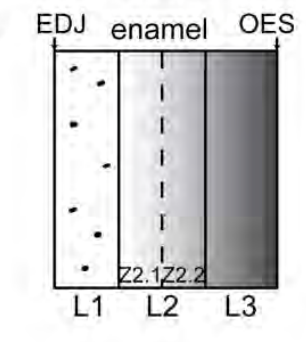

\begin{tabular}{llll}
\hline L1 & L2 & L3
\end{tabular}

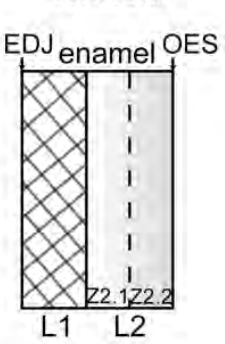

Figure 10. Sketches of the main characteristics of the division of the enamel in the species studied: $\mathrm{S}$. coronatus, B. fissidens, D. glyphodon, Terricola and Crocidura. Indicated are the number of divisions, the type of enamel of each one, whether or not tubules are present, and the Fe content.

$105 \times 64 \mathrm{~mm}(600 \times 600 \mathrm{DPI})$

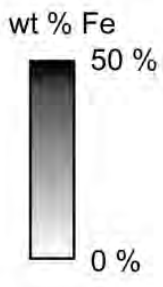



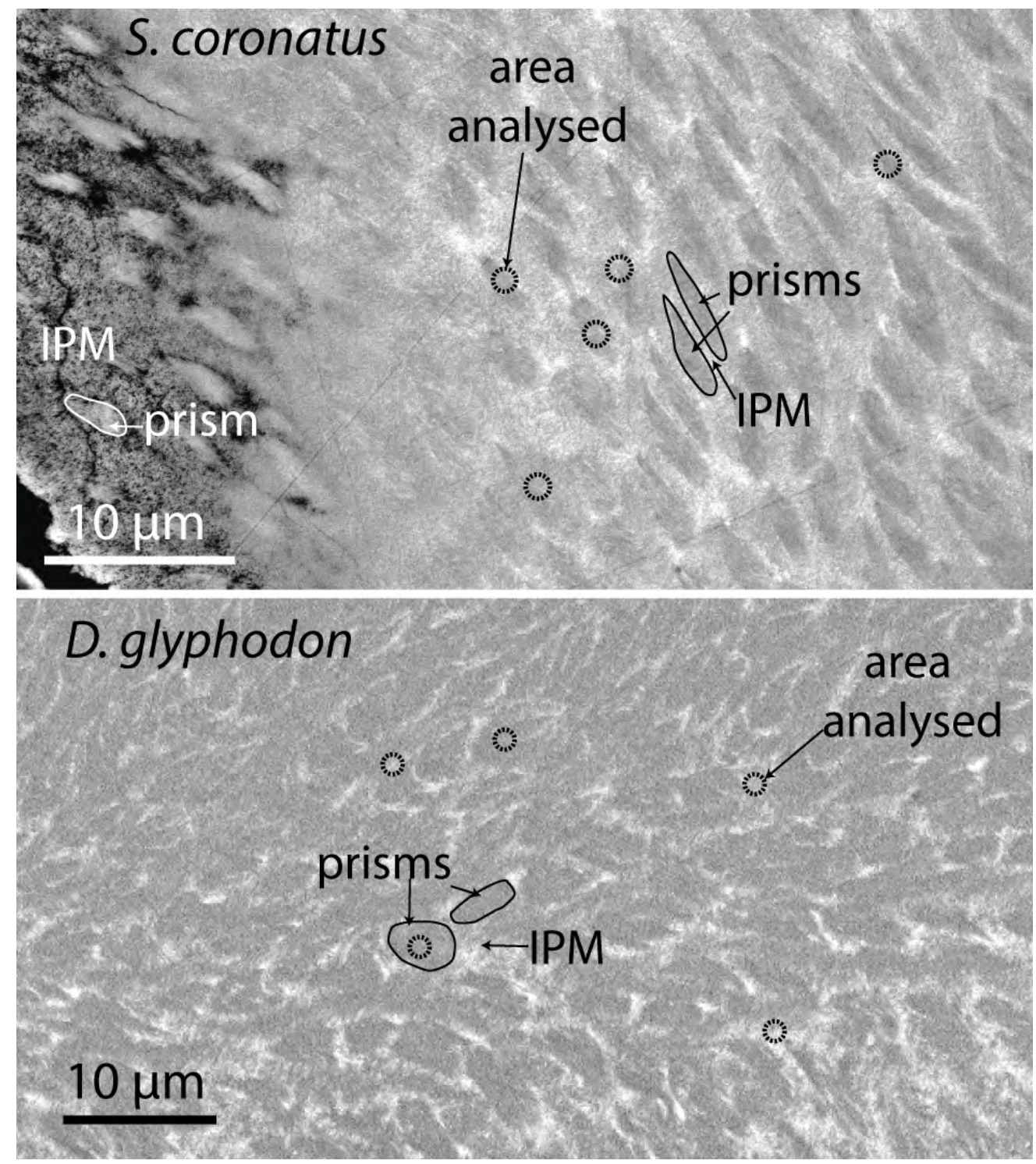

Figure 11. Example of the size of the areas analysed by point EDS analysis (circles) compared with the size of the enamel prisms of S. coronatus and D. glyphodon. Note that the analyses of D. glyphodon can be performed on a single element, whereas in S. coronatus this is more difficult. In the image of S. coronatus the grey of the IPM differs visibly in the layer with Fe (white) from without Fe (dark grey-black).

$80 \times 90 \mathrm{~mm}(300 \times 300 \mathrm{DPI})$ 


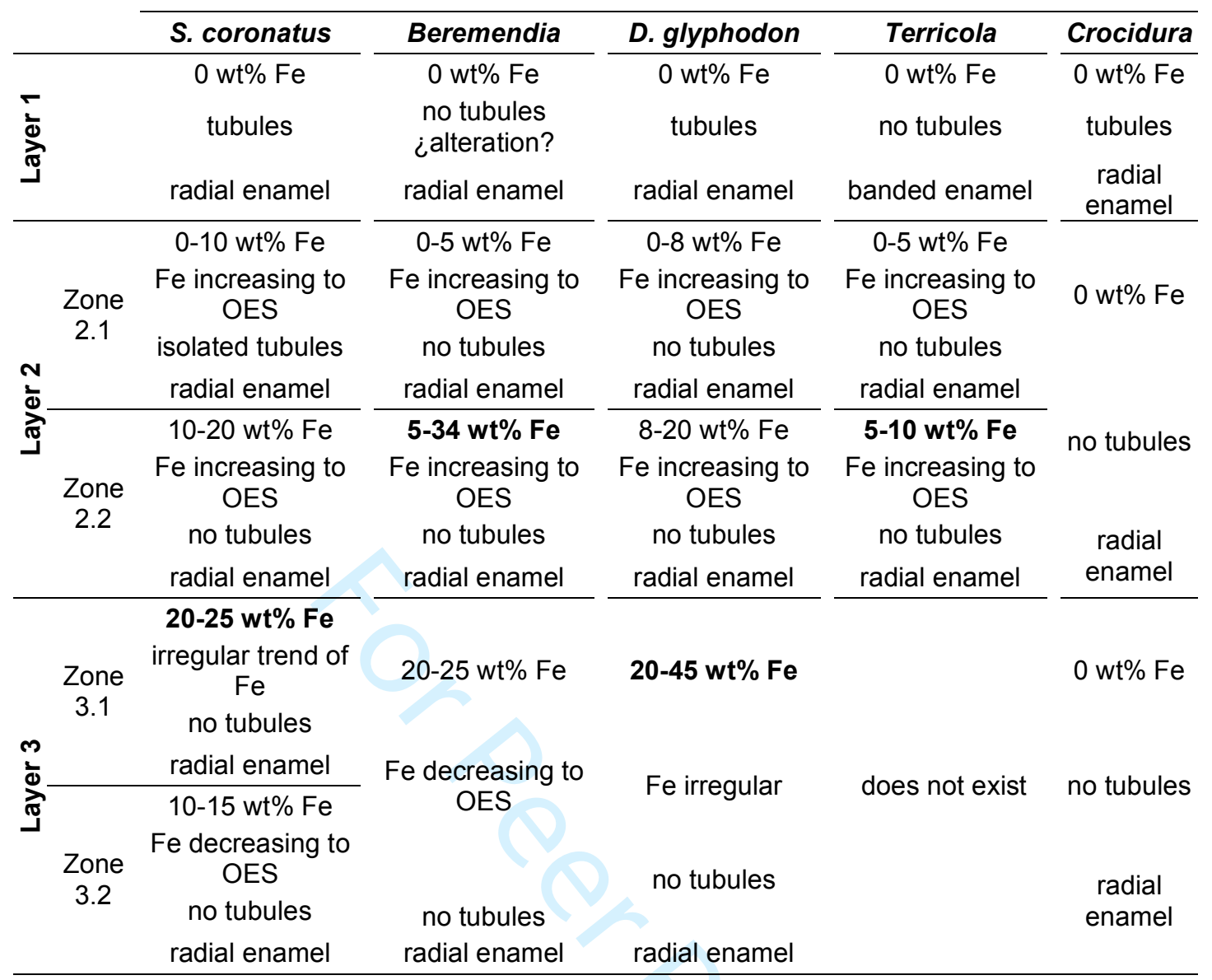

Table 1. Summary of the main characteristics of the division of enamel in the species studied. In bold the highest quantities of $\mathrm{Fe}$ in each species. 


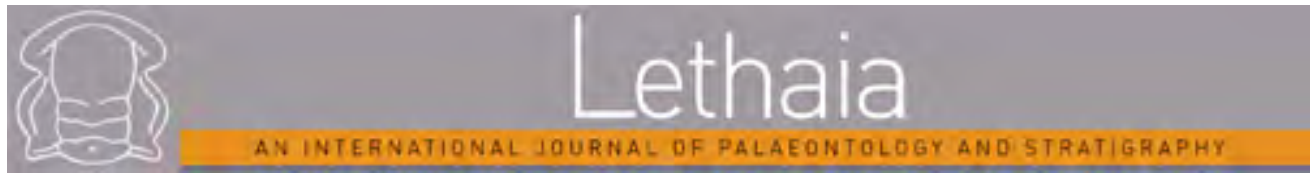

\section{Structure and composition of the incisor enamel of extant and fossil mammals with tooth pigmentation}

\begin{tabular}{|r|l|}
\hline Journal: & Lethaia \\
\hline Manuscript ID & LET-OA-03-18-0797.R2 \\
\hline Manuscript Type: & Original Article \\
\hline Author: & $\mathrm{n}$ /a \\
\hline Complete List of Authors: & $\begin{array}{l}\text { Moya-Costa, Raquel; Universidad de Zaragoza Facultad de Ciencias, } \\
\text { Ciencias de la Tierra; Instituto Universitario de Ciencias Ambientales de } \\
\text { Aragón (IUCA) } \\
\text { Bauluz, Blanca; University of Zaragoza, Ciencias de la Tierra; Instituto } \\
\text { Universitario de Ciencias Ambientales de Aragón (IUCA) } \\
\text { Cuenca-Bescós, Gloria; Universidad de Zaragoza, Paleontology; Instituto } \\
\text { Universitario de Ciencias Ambientales de Aragón (IUCA) }\end{array}$ \\
\hline Keywords: & Soricid, Enamel, Rodent, Red teeth, EDS, TEM, I ron \\
\hline
\end{tabular}

